Crônicas de direito internacional ............................................................. Julia Motte-Baumvol e Alice Rocha da Silva

BRAZILIAN TRADE POLICY IN HISTORICAL PERSPECTIVE: CONSTANT FEATURES, ERRATIC BEHAVIOR..11 Paulo Roberto de Almeida

Aspectos GEopolíticos do GAT'T E DA OMC .........................................................28 José Fontoura Costa

A REgulaÇÃo INTERNACIONAL dos SUbSídios AGRÍCOLAS: A CONTEMPORANEIDADE DO PARADIGMA REALISTA PARA A COMPREENSÃO DO SISTEMA DE COMÉRCIO AGRÍCOLA INTERNACIONAL VIGENTE

Natália Fernanda Gomes

ACORDO TRIPS: ONE-SIZE-FITS-ALL?

Tatianna Mello Pereira da Silva

É INTERESSANTE PARA O BRASIL ADERIR AO ACORDO SOBRE COMPRAS GOVERNAMENTAIS DA OMC?

Clarissa Chagas Sanches Monassa e Aubrey de Oliveira Leonelli

A Defesa COMERCIAL E A RESTRIÇÃo dA LIBERALIZAÇÃo E DA INTEGRAÇÃo COMERCIAL PELO AUMENTO DA ALÍQUOTA DE IPI DE VEÍCULOS IMPORTADOS NO BRASIL...................................86

Ricardo Serrano Osorio e Clayton Couto

A COOPERAÇÃo INTERNACIONAL NA DEFESA DA CONCORRÊNCIA

Vinicius Marques de Carvalho e Paulo Burnier da Silveira

Os ACORDOS DE COMÉRCIO PARA ALÉM DAS PREFERÊNCIAS: UMA ANÁLISE DA REGULAMENTAÇÃO SOBRE OS "NOVOS TEMAS" 105

Michelle Ratton Sanchez Badin e Lucas da Silva Tasquetto

INTEGRAÇÃO ECONÔMICA NO MERCOSUL: OPINIÕES CONSULTIVAS E A DEMOCRATIZAÇÃO NO ACESSO AO TRIBUNAL PERMANTE DE REVISÃO 128 Eduardo Biachi Gomes

"Fundos abutres" vs. Estados NaCionais: SObERANiA E ATUAÇÃo do Tribunal INTERNACIONAL do Direito do Mar a partir do Caso da Fragata libertad.. 138 Alexandre Pereira da Silva e Mariana Yante Barrêto Pereira

INVESTIMENTO ESTRANGEIRO: O PADRÃO DE TRATAMENTO JUSTO E EQUITATIVO E O PAPEL DA BOA-FÉ 
Fernando Santos Arenhart

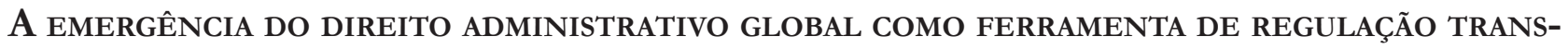
NACIONAL DO INVESTIMENTO ESTRANGEIRO DIRETO .................................................. 171

Andréa Rocha Postiga

Is INVESTMENT ARBITRATION AN APPROPRIATE VENUE FOR ENVIRONMENTAL ISSUES? A LATIN AMERICAN PERSPECTIVE.

Nitish Monebhurrun

A jurisprudência do Superior Tribunal de Justiça e a construção de um Conceito de

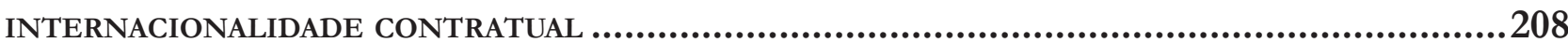

Frederico E. Z. Glitz

IMPACTO E INFLUÊNCIA DOS TRATADOS E CONVENÇÕES INTERNACIONAIS SOBRE A LEI BRASILEIRA DE ARBITRAGEM

Jamile Bergamaschine Mata Diz e Clarissa Correa Neto Ribeiro

A JURISPRUdÊNCIA NORTEAMERICANA E EUROPEIA SOBRE OS ACORDOS HORIZONTAIS E VERTICAIS: SUBSTRATO PARA ANÁLISE DA MATÉRIA NO BRASIL.

Daniel Amin Ferraz 


\section{A emergência do direito administrativo global como ferramenta de regulação transnacional do investimento estrangeiro direto}

\author{
The emergence of the global administrative \\ law as a means of transnational regulation of \\ foreign direct investment*
}

\section{Resumo}

O Direito Administrativo Global aparece no cenário do investimento estrangeiro direto como uma resposta aos atos praticados em âmbito nacional que repercutem em escala global. As críticas apresentadas, no que toca a sua aplicação à regulação do investimento estrangeiro, giram principalmente em torno de questões como a responsabilização e a prestação de contas no exercício do poder regulatório transnacional (accountability), a legitimidade do sistema proposto, bem como o seu caráter democrático e a sua efetividade. No entanto, acredita-se que o Direito Administrativo Global possa vir como resposta às questões não resolvidas nesse cenário. Para este estudo, discorre-se acerca do investimento estrangeiro direto, na primeira parte, passando-se pelo histórico de sua regulação, desenvolvimento e panorama atual. A transição para o segundo momento parte da argumentada fragmentariedade da forma de tratamento hoje dispensada ao investimento estrangeiro no plano internacional, introduzindo-se então o paradigma do Direito Administrativo Global como nova via regulatória, apresentando-se o conceito idealizado, bem como as estruturas por meio das quais opera na esfera do investimento estrangeiro direto. $\mathrm{O}$ ensaio conclui apontando as questões a serem superadas para que a introdução desta nova proposta não cause prejuízos. Buscam-se alternativas capazes de fazer com que o público e o privado dialoguem da melhor forma possível para a construção de um padrão internacional nesta seara. Depreende-se do estudo realizado é que o Direito Administrativo Global tenta propor uma via delimitadora dessas novas e diversas relações, a fim de impedir abusos de ambas as partes, aproximando-se dos padrões almejados.

Palavras-chave: Direito Administrativo Global. Globalização. Investimento Estrangeiro Direto. Arbitragem. Redes Intergovernamentais.

\section{Abstract}

The Global Administrative Law appears in the scenario of foreign direct investment as a response to actions taken at the national level that have impact on a global scale. The criticisms made with regard to its application 
to the regulation of foreign investment, mainly revolve around issues such as accountability in the exercise of transnational regulatory power, the legitimacy of the proposed system and its democratic character and its effectiveness. However, it is believed that the Global Administrative Law may come as a response to unsolved issues in this scenario. For this study, the first part is dedicated to an approach of the foreign direct investment itself, from the history of its regulation and development to the current situation. The transition to the second moment departs from the fragmentation which is argued concerning the treatment now given to foreign investment internationally. It is then introduced the paradigm of Global Administrative Law as a new regulatory pathway, presenting its idealized concept as well as the structures through which it operates in the sphere of foreign direct investment. The essay concludes by identifying the issues to be overcome for the introduction of this new proposal, without causing any damages. Alternatives able to make the public and private sectors engage in dialogue in the best possible way for the construction of an international standard in this endeavor are then seak. What is clear from the study is that the Global Administrative Law tries to propose a way linking these new and diverse relationships, in order to prevent abuses from both sides, approaching the desired patterns.

Key-words: Global Administrative Law. Globalization. Foreign Direct Investment. Arbitration. Intergovernmental Networks

\section{INTRODUÇÃo}

A interdependência globalizada em diferentes campos da vida, no contexto da nova ordem mundial, ${ }^{2}$ acabou por gerar a regulação transnacional das diversas áreas em que uma multiplicidade de relações jurídicas tornava-se crescentemente entrelaçada. Desde então, evidenciou-se a necessidade de um controle capaz de gerir e disciplinar estas novas relações surgidas em domínios, como: seguros; desenvolvimento e financia-

2 SLAUghter, Anne-Marie. A New World Order. Princeton: Princeton Univerity Press, 2004. e SLAUGHTER, Anne-Marie. Global Government Networks, Global Information Agencies, and Disaggreagated Democracy. Working Paper n. 18. Cambridge: Harvard Law School, 2001. Disponível em: <http://papers.ssrn.com/sol3/papers.cfm?abstract_id=283976>. Acesso em: 11 jan. 2013 p. 2. mento dos países em desenvolvimento; proteção ambiental; setor bancário; regulação financeira; execuções judiciais; telecomunicações; comércio de produtos e serviços; propriedade intelectual; standards de direitos dos trabalhadores; migrações e refugiados. ${ }^{3}$

Outra seara que acabou por ser igualmente objeto dessa espécie de regulação, revelando a pertinência do estudo desse fenômeno para compreensão do enfoque desta análise, seria a da regulação e gerência do investimento estrangeiro direto ${ }^{4}$ em escala global por esta nova forma de governança, que passa a ser denominada Global Administrative Law (Direito Administrativo Global). ${ }^{5}$ Os fluxos de investimento são hoje quatro vezes maiores do que os fluxos de comércio internacional, assumindo proporções que ultrapassam os limites das possibilidades regulatórias domésticas. ${ }^{6}$

A emergência de redes transnacionais de atuação no plano internacional para elaboração dessa regulação e a instituição de mecanismos e de padrões foram a sequência natural deste processo de características peculiares. $^{7} \mathrm{O}$ sistema abrange estruturas, procedimentos e padrões normativos, aplicáveis a órgãos regulatórios intergovernamentais formais, aos órgãos informais e redes transgovernamentais, a órgãos "híbridos" público-privados e a órgãos privados transnacionais.

Polarizam-se dois campos de opinião bastante distintos nessa seara, divididos entre aqueles que tendem a crer que a melhor forma de regulação desta realida-

3 KINGSBURY, Benedict; KIRSCH, Nico; STEWART, Richard B. The Emergence of Global Administrative Law. Global Administrative Law Series. IILJ Working Paper 2004/1. Disponível em: < http:// www.iilj.org/GAL/documents/TheEmergenceofGlobalAdministrativeLaw. pdf>. Acesso em: 11 jan. 2013. p. 3.

${ }_{4}$ Seria o investimento feito por um residente de um Estado, com interesse de longa duração, em uma empresa situada em outro Estado. É o que distingue o investimento estrangeiro indireto do investimento de portfólio, em que o capital estrangeiro é simplesmente detido por acionistas de forma passiva, sem que lhe interesse a manutenção a longo prazo da relação. ALVAREZ, José E. The Public International Law Regime Governing International Investment. Recueil des cours, v. 344. Pocketbooks of the Hague Academy of International Law, 2009. p. 6.

5 ALVAREZ, José E. The Public International Law Regime Governing International Investment. Recueil des cours, v. 344. Pocketbooks of the Hague Academy of International Law, 2009. p. 326

6 POULSEN, Lauge Skovgaard; HUFBAUER, Gary Clyde. Foreign Direct Investment in Times of Crisis. Working Paper Series 11-3. Washington: Peterson Institute for International Economics, 2011. p. 3-4.

ALVAREZ, José E. The Public International Law Regime Governing International Investment. Recueil des cours, v. 344. Pocketbooks of the Hague Academy of International Law, 2009. p. 327 
de emergente seria pela adoção de um modelo formal, criando-se instituições internacionais estabelecidas por meio de tratados e acordos formais entre Estados, e aqueles partidários de uma governança baseada em redes de cooperação e formas intergovernamentais menos rígidas. ${ }^{8}$

É neste segundo grupo, portanto, que se enquadram os propagadores da Global Administrative Law, ou do Direito Administrativo Global, em que a tomada de decisões regulatórias passa do nível nacional para o global, por meio de órgãos administrativos transnacionais, sejam estes organizações internacionais ou grupamentos menos formais de oficiais que desempenham funções administrativas, mas que não estão diretamente subordinados aos governos nacionais ou aos sistemas legislativos domésticos. Nesse sistema, as decisões regulatórias podem ser implementadas diretamente contra os entes privados ou por meio da introdução de mudanças nos regimes e regulações nacionais. ${ }^{9}$

Nesse contexto, a Global Administrative Law (GAL) vem como uma resposta aos atos praticados em âmbito nacional que repercutem em escala global, nas mais diversas áreas. As críticas apresentadas, no que toca a sua aplicação à regulação do investimento estrangeiro, giram principalmente em torno de questões como a responsabilização e prestação de contas no âmbito do exercício do poder regulatório transnacional (accountability), a legitimidade do sistema proposto, bem como o seu caráter democrático e a sua efetividade.

Nessa esteira, a intenção subjacente à redação deste artigo consiste em fornecer uma análise dos fundamentos, da lógica, da estrutura, do funcionamento e dos problemas inerentes ao atual sistema de direito internacional aplicado ao investimento, para melhor compreensão das questões em seu entorno e dos fenômenos decorrentes do aumento das trocas comerciais nas últimas décadas, que provocou sérias alterações no cenário econômico mundial. Dá-se ênfase ao estudo do Direito Administrativo Global como forma de regulação emergente na seara do investimento, apresentando-se seus entornos, fundamentos e aplicabilidade neste âmbito.

\footnotetext{
8 GRAHME F, Thompson. The constitutionalization of the global corporate sphere? Oxford: Oxford University Press, 2012.

9 SLAUGHTER, Anne-Marie. Global Government Networks, Global Information Agencies, and Disaggreagated Democracy. Working Paper n. 18. Cambridge: Harvard Law School, 2001. Disponível em: < http://papers.ssrn.com $/$ sol3 $/$ papers.cfm?abstract_id $=283976>$. Acesso em: 11 jan. 2013. p. 3
}

Tais questões integram a pauta das discussões periódicas que tem lugar entre os atores envolvidos, buscando promover adequada regulação no domínio do investimento, de magnitude crescente nas últimas décadas.

Para este estudo, discorre-se acerca do investimento estrangeiro direto, na primeira parte, passando-se pelo histórico de sua regulação, desenvolvimento e panorama atual. A transição para o segundo momento parte da argumentada fragmentariedade da forma de tratamento hoje dispensada ao investimento estrangeiro no plano internacional, introduzindo-se então o paradigma do Direito Administrativo Global como nova via regulatória, apresentando-se o conceito idealizado, bem como as estruturas por meio das quais opera na esfera do investimento estrangeiro direto. $\mathrm{O}$ ensaio conclui apontando as questões a serem superadas para que a introdução do sistema do Direito Administrativo Global dê-se de forma a não causar prejuízos a nenhum dos atores envolvidos nestas relações de tão amplo alcance atualmente.

\section{REGIME INTERNACIONAL DE DISCIPLINA DO IN- VESTIMENTO ESTRANGEIRO}

\subsection{Investimento estrangeiro direto e sua disci- plina}

Foi a partir do final da Segunda Guerra Mundial que o atual regime de regulação do investimento estrangeiro direto (IED) começou a ser desenhado. Trata-se de uma relação que ocorre com maior frequência por meio de uma fusão ou aquisição de uma firma nacional, ainda que também possa ocorrer pelo estabelecimento de uma empresa nova (modalidade esta conhecida por greenfield investment) ou pela aquisição de um percentual com o qual tenha o controle do capital da empresa. ${ }^{10}$ Essencialmente, o IED consiste na existência de uma relação de longo prazo entre um investidor direto e seu afiliado estrangeiro, o que, via de regra, representa significativo grau de influência no controle daquela empresa.

Ainda que haja grande discussão em torno dos efeitos, se benéficos ou não, da presença e incentivo ao investimento estrangeiro direto como via para promover

10 ALVAREZ, José E. The Public International Law Regime Governing International Investment. Recueil des cours, v. 344. Pocketbooks of the Hague Academy of International Law, 2009. p. 7. 
o crescimento econômico de países em desenvolvimento, o fato é que estes fluxos tiveram considerável aumento nas duas últimas décadas, vindo, porém, a sofrer algumas quedas desde o início do período de recessão mundial, iniciado no ano de 2008. De acordo com a Conferência das Nações Unidas para o Comércio e o Desenvolvimento (CNUCED), no ano de 2012, os fluxos de investimento declinaram de 1.6 trilhões de dólares, em 2011, para 1.3 trilhões, o que representa uma queda de $18 \%$ em relação aos índices registrados no ano anterior. $^{11}$

A análise geral, contudo, é a de que esses episódios de queda sejam decorrência das sucessivas crises e recessões vivenciadas recentemente, e, portanto, efêmeros, de modo que a tendência global de aumento desses fluxos, observada nas últimas décadas, permanece. Sendo que a tendência de recuperação no setor, as trocas comerciais e os fluxos de investimento, desde há muito, demandam regulação efetiva, para que estas relações ocorram de forma regrada, sem prejuízo aos interesses de nenhum dos atores envolvidos. As maiores fontes de controvérsia na matéria giram em torno de questões econômicas, políticas e de segurança nacional. ${ }^{12}$

A América Latina é um exemplo de caso em que correntes esquerdistas tentaram coibir a recepção do investimento estrangeiro direto pelos governos dos países do continente. Entretanto, tal prática não vigorou, destacando-se como exemplo de superação desta postura o caso do Brasil, um dos Estados com maiores fluxos de investimento, tanto de saída quanto de entrada, entre os países da América Latina.

No plano econômico, manifestam-se receios como os de que as empresas instaladas empreguem menos nacionais, marginalizem empresas existentes, monopolizem determinados setores. No âmbito político, teme-se que as empresas estrangeiras corrompam políticos, se insiram em assuntos nacionais não pertinentes, violem leis locais ou normas culturais e não respeitem o meio-ambiente. A este propósito, inclusive, argui-se que certas disposições constantes de tratados de investimento estariam coibindo o direito de o Estado hospedeiro

\footnotetext{
11 CNUCED. Global Investment Trends Monitor. n. 11, 2013. Disponível em: <http://unctad.org/en/PublicationsLibrary/webdiaeia2013d1_en.pdf>. Acesso em: 11 jan. 2013. p. 1.

12 POULSEN, Lauge Skovgaard; HUFBAUER, Gary Clyde. Foreign Direct Investment in Times of Crisis. Working Paper Series 11-3. Washington: Peterson Institute for International Economics, 2011. p. 10-11.
}

exercer seu poder regulatório em prol do interesse público em determinados assuntos. ${ }^{13}$

Dentre as preocupações com a segurança pública do Estado hospedeiro do investimento, destacam-se questões como o medo de que essas empresas controlem o acesso a áreas eminentemente nacionais, como tecnologia de defesa, e também de que manipulem os interesses nacionais, assumindo a posição do mercado como agente, para manejar seus próprios interesses e os de seus Estados de origem. ${ }^{14}$

A recorrência desse gênero de preocupações, aliada ao aumento dos fluxos de investimento, teve como consequência automática o desencadeamento de um processo de legalização do investimento estrangeiro, representado pela proliferação de normas legais regulatórias que passaram a constar tanto das leis internas dos Estados quanto de práticas administrativas, direito internacional costumeiro, tratados, princípios gerais do Direito e de instrumentos de origem institucional, dando origem a um sistema hoje apontado como fragmentário pelos seus atores.

A evolução desse material normativo fica por conta do aperfeiçoamento de suas previsões nos documentos de consolidação, mas também pela prática dos tribunais arbitrais responsáveis pela resolução dos litígios entre Estados e investidores. Trata-se de um dos domínios em que ocorre uma delegação implícita, por parte do Estado, de seu poder regulatório sobre o assunto, a órgãos internacionais, como o Fundo Monetário Internacional (FMI) e o Banco Mundial (BM), e também a instituições de vocação internacional ligadas à temática, como seria o caso da Conferência das Nações Unidas sobre Comércio e Desenvolvimento (CNUCED) e da Organização para Cooperação e Desenvolvimento Econômico (OCDE). ${ }^{15}$

Peculiar na seara do investimento é a inexistência de um regime $e^{16}$ próprio para seu regramento e disciplina,

13 ALVAREZ, José E. The Public International Law Regime Governing International Investment. Recueil des cours, v. 344. Pocketbooks of the Hague Academy of International Law, 2009. p. 9

14 ALVAREZ, José E. The Public International Law Regime Governing International Investment. Recueil des cours, v. 344. Pocketbooks of the Hague Academy of International Law, 2009. p. 10

15 ALVAREZ, José E. The Public International Law Regime Governing International Investment. Recueil des cours, v. 344. Pocketbooks of the Hague Academy of International Law, 2009. p. 11

16 A exemplo da lição de Alvarez (2009, p. 11 e capítulo final), emprega-se aqui o termo "regime", em detrimento do termo "sistema” em razão de ao primeiro não ser atribuída a mesma implicação 
o que se traduz na ausência tanto de um instrumento multilateral que represente a concordância em torno de um sistema proposto, quanto de uma instituição formal responsável pelo exercício do poder regulatório e adjudicativo neste âmbito, a exemplo do que se verifica hoje com relação ao comércio internacional, fundado sobre o Acordo Geral de Tarifas e Comércio (GATT), amparado institucionalmente pela Organização Mundial do Comércio (OMC).

As tentativas de elaboração de um regime único para o regramento multilateral do investimento estrangeiro pela comunidade internacional remontam a 1948, com a tentativa de criação de uma organização internacional do comércio, que abrangeria também as questões de investimento por meio da Carta de Havana. Esta tentativa não vingou, tendo permanecido tão somente o GATT desta empreitada.

Desde então, chama-se atenção para os esforços dos estudiosos da Faculdade de Direito de Harvard, em 1961, destacando-se o trabalho dos professores Louis Sohn e Richard Baxter, na elaboração do que viria a ser a Convenção sobre a Responsabilidade Internacional dos Estados por Prejuízos Causados a Terceiros, igualmente frustrada. A este ensaio, seguiram-se outros dois documentos elaborados pela OCDE: no ano de 1963, foi elaborada a Convenção da OCDE para proteção da propriedade estrangeira (OECD Draft Convention on Protection of Foreign Property) e o Acordo Multilateral sobre Investimento (Multilateral Agreement on InvestmentMAI), elaborado em 1967.

O primeiro projeto teria sido frustrado em razão da cisão ideológica existente entre países exportadores de capital e países importadores de capital em torno de quais deveriam ser os princípios norteadores da proteção do investimento. O plano parecia demasiado ambicioso, tendo em vista que os movimentos pela Nova Ordem Econômica vinham ganhando forças no cenário internacional. ${ }^{17}$ Essa cisão ideológica viria a se dissipar nos idos dos anos de 1990, quando se ensaiou a aprovação segundo projeto, o Acordo Multilateral sobre In-

normativa característica do segundo, que pressupõe igualmente estrutura mais organizada do que a verificada hoje no regime de investimento.

17 KINGSBURY, Benedict; KIRSCH, Nico; STEWART, Richard B. The Emergence of Global Administrative Law. Global Administrative Law Series. IILJ Working Paper 2004/1. Disponível em: < http:// www.iilj.org/GAL/documents/TheEmergenceofGlobalAdministrativeLaw. pdf>. Acesso em: 11 jan. 2013. p. 50. vestimento, mas que novamente termina por falhar em 1998.

Esse fracasso, juntamente com as tentativas frustradas por parte da OMC, teria sido decorrente da falta de convergência de posicionamentos e interesses entre os diferentes atores desse cenário, envolvidos nas negociações, de forma direta ou indireta. Não se teria chegado ao acordo entre as diferentes partes em torno dos princípios gerais de proteção do investimento, havendo exceções e isenções de todas as partes. ${ }^{18}$

Ensaios para regulação pela soft law, como intentou a Assembleia Geral das Nações Unidas, em suas resoluções de 1962 e 1973, concernentes à Soberania Permanente sobre os Recursos Naturais, à Carta dos Direitos e Deveres Econômicos dos Estados (CERDS), ao lado do regramento voluntário da OCDE, sobre as Diretrizes para Empresas Multinacionais da Conferência das Nações Unidas para o Comércio e o Desenvolvimento (CNUCED), e do Código de Conduta das Nações Unidas para Empresas Transnacionais, tiveram, contudo, significativo impacto no que viria a constituir a atual regulação do IED. ${ }^{19}$

O regime que se tem hoje é o resultado do material reunido pelas tentativas frustradas de regulação multilateral e por uma série de documentos elaborados desde o início das tentativas. Este acervo inclui Tratados Bilaterais de Investimento (BITs); Acordos de Livre Comércio (tal como o Capítulo 11, do North America Free Trade Agreement - NAFTA), o Energy Charter Treaty (ECT); os acordos da OMC, entre os quais o acordo sobre Medidas de Investimento Relacionadas ao Comércio (TRIMs), o Acordo Geral sobre Serviços (GATs), e o Acordo sobre Aspectos dos Direitos de Propriedade Intelectual (TRIPs); um relevante número de resoluções e outros instrumentos de soft law da Assembleia Geral das Nações Unidas (como as Diretrizes da OCDE), o Código da OCDE sobre Movimento de Capitais; o Centro Internacional para Solução de Controvérsias em Investimentos do Banco Mundial (ICSID), assim como

\footnotetext{
18 RIPINSKI, Sergey. Stephan W. Schill. The Multilateralization of International Investment Law - Book Review. European Journal of International Law, v. 22, n. 2, p. 598-602. Oxford: Oxford University Press, 2011. Disponível em: <http://ejil.oxfordjournals.org/content/22/2/598.full.pdf + html>. Acesso em: 11 jan. 2013. p. 2 19 SCHILL, Stephan W. The Multilateralization of International Investment Law. Online Proceedings, Working Paper n. 18/08. London: Society of International Economic Law, 2008. Disponível em: <http://www.ssrn.com/link/SIEL-Inaugural-Conference.html>. Acesso em: 11 jan. 2013. p. 23-64.
} 
outros mecanismos arbitrais, como a UNICITRAL; e a Agência Multilateral de Garantia do Investimento (MIGA). ${ }^{20}$

O que pareceu se consolidar nos últimos anos foi a crescente tendência de celebração de tratados bilaterais de investimento (BITs), representando não um desacordo em torno de princípios gerais em si, tal como ocorrido em torno dos ensaios à celebração de tratados multilaterais, mas a intenção de formulação de condições específicas para cada caso. O surgimento dos Tratados Bilaterais de Investimento (BITs) deu-se a partir das aspirações e abordagens apresentadas nas negociações dos tratados multilaterais de investimento, resultando em grande uniformidade quando da elaboração dos tratados bilaterais, já que faziam uso basicamente da mesma estrutura. Como resultado, verificou-se uma reincidência de princípios entre os documentos firmados bilateralmente. ${ }^{21}$

O regime dos BITs e a maneira como influencia a configuração do cenário atual do investimento estrangeiro direto no plano internacional serão objeto de análise do ponto subsequente deste estudo.

\subsection{Regime dos BITs: cartilha do investimento estrangeiro direto}

Aos poucos, foi-se formando um corpo de princípios gerais, extraídos desta documentação, que passou a reger as relações envolvendo o investimento estrangeiro, destacando-se aí princípios como o da não discriminação, do tratamento justo e equitável, da proteção contra expropriação direta e indireta, do uso de cláusulas guarda-chuvas e de provisões para transferência de capitais, além do mecanismo de solução de controvérsias previsto. ${ }^{22}$

Após o período das descolonizações, período intenso de expropriações, e o final da Guerra Fria, esses prin-

\footnotetext{
20 ALVAREZ, José E. The Public International Law Regime Governing International Investment. Recueil des cours, v. 344. Pocketbooks of the Hague Academy of International Law, 2009. p. 13

21 RIPINSKI, Sergey. Stephan W. Schill. The Multilateralization of International Investment Law - Book Review. European Journal of International Law, v. 22, n. 2, p. 598-602. Oxford: Oxford University Press, 2011. Disponível em: <http://ejil.oxfordjournals.org/content/22/2/598.full.pdf + html $>$. Acesso em: 11 jan. 2013. p. 2

22 RIPINSKI, Sergey. Stephan W. Schill. The Multilateralization of International Investment Law - Book Review. European Journal of International Law, v. 22, n. 2, p. 598-602. Oxford: Oxford University Press, 2011. Disponível em: <http://ejil.oxfordjournals.org/content/22/2/598.full.pdf+html>. Acesso em: 11 jan. 2013. p. 2
}

cípios foram não somente aceitos, mas promovidos por países em desenvolvimento e economias de transição. Tanto que a tendência apresentada desde o início fora a de celebração dos ditos instrumentos, no mais das vezes, entre um país desenvolvido e um país em desenvolvimento ou economia emergente. Gráficos apresentados pelo Banco Mundial, em seu Relatório de 2011, refletem esta tendência, demonstrando que estes tratados eram prioritariamente formas de garantia, pelos países desenvolvidos, de que seus investidores teriam seus contratos de investimento adimplidos, amparados pela possibilidade ainda de, em caso de inadimplemento, verem-se reparados pelos danos sofridos. ${ }^{23}$

Entretanto, com o passar dos anos e a alteração do cenário econômico, a partir do surgimento das economias emergentes, observou-se uma tendência também na celebração de BITs entre países em desenvolvimento. Curiosamente, nestes casos, verificou-se que os tratados celebrados abarcavam as mesmas disposições identificadas quando da celebração de tratados bilaterais entre países desenvolvidos e países em desenvolvimento. ${ }^{24}$ Schill aponta três razões de ser deste fenômeno: mudança ideológica; prática dos governos em copiar os modelos anteriores de BITs; ou o fato de que sempre, em uma relação de investimento, independentemente do nível de desenvolvimento das partes celebrantes, haverá uma que se sente em posição de país exportador de capital. ${ }^{25}$

Nesse passo, ainda que sejam identificadas diferenças entre BITS, isto não significa dizer que eles não convirjam no que toca aos seus elementos principais. A presença do princípio da nação mais favorecida, que impede a concessão de benefícios especiais a investidores de Estados específicos, em detrimento de outros, prevendo um tratamento igualitário no âmbito internacional, seria o instrumento-chave capaz de afastar as

23 WORLD BANK. Multipolarity: The New Global Economy. 104-117, 2011. Disponível em: < http://siteresources.worldbank.org/INTGDH/Resources/GDH_CompleteReport2011.pdf>. Acesso em : 11 jan. 2013.

24 RIPINSKI, Sergey. Stephan W. Schill. The Multilateralization of International Investment Law - Book Review. European Journal of International Law, v. 22, n. 2, p. 598-602. Oxford: Oxford University Press, 2011. Disponível em: <http://ejil.oxfordjournals.org/content/22/2/598.full.pdf + html $>$. Acesso em: 11 jan. 2013. p. 3

25 RIPINSKI, Sergey. Stephan W. Schill. The Multilateralization of International Investment Law - Book Review. European Journal of International Law, v. 22, n. 2, p. 598-602. Oxford: Oxford University Press, 2011. Disponível em: <http://ejil.oxfordjournals.org/content/22/2/598.full.pdf + html>. Acesso em: 11 jan. 2013. p. 3 
diferenças entre os níveis de proteção oferecidos pelos tratados individuais, o que resultaria em uma multilateralização, em última análise, do sistema internacional regulatório do investimento. ${ }^{26}$

O Brasil, por exemplo, em que pese seja signatário de mais de 15 BITs, não ratificou nenhum deles, ao contrário dos outros países, e, por esta razão, não tem nenhum BIT em vigor. Em casos como este, o país é considerado externo e não participante do sistema multilateral de investimentos. Mas no momento em que um país assina um BIT, este já passa automaticamente a integrar o sistema multilateral, pois o efeito de um BIT típico não se restringe a uma única relação bilateral específica, que seria aquela de destinação do tratado. Da mesma forma, pela incidência da cláusula da nação mais favorecida, o investidor pode escolher, dos BITs firmados pelo país com quem está contratando, aquele que mais se adequa aos seus objetivos e a suas necessidades. Em razão da não discriminação, o Estado será obrigado a fornecer as mesmas condições de celebração. ${ }^{27}$

O sistema dos BITs gera consideráveis controvérsias entre os estudiosos do assunto. Autores que levaram a análise a fundo, como Guzman ${ }^{28} \mathrm{e}$ Alvarez, ${ }^{29}$ concordam que o sistema seria inevitável, aceitando o fato de que os BITs foram a saída encontrada para atribuir medidas de proteção adequadas tanto para investidores quanto para hospedeiros. Os BITs seriam assim uma garantia para o investidor, em países cujo governo não elaborou uma legislação suficientemente justa para a matéria, repercutindo ainda como fator de atração do investimento, tendo em conta que a segurança para o investidor naquele Estado será sustentada por um tratado. ${ }^{30}$

26 RIPINSKI, Sergey. Stephan W. Schill. The Multilateralization of International Investment Law - Book Review. European Journal of International Law, v. 22, n. 2, p. 598-602. Oxford: Oxford University Press, 2011. Disponível em: <http://ejil.oxfordjournals.org/content/22/2/598.full.pdf + html>. Acesso em: 11 jan. 2013. p. 3

27 RIPINSKI, Sergey. Stephan W. Schill. The Multilateralization of International Investment Law - Book Review. European Journal of International Law, v. 22, n. 2, p. 598-602. Oxford: Oxford University Press, 2011. Disponível em: <http://ejil.oxfordjournals.org/content/22/2/598.full.pdf+html>. Acesso em: 11 jan. 2013. p. 3

28 GUZMAN, Andrew T. "Why LDCs Sign Treaties That Hurt Them: Explaining the Popularity of Bilateral Investment Treaties", 38 Virginia Journal of International Law, 639, 1998.

29 ALVAREZ, José E. The Public International Law Regime Governing International Investment. Recueil des cours, v. 344. Pocketbooks of the Hague Academy of International Law, 2009.

30 Notas do curso ministrado pelo prof. Fábio Morosini, no $2^{\circ}$ semestre de 2012, sobre Regulação do Comércio Internacional e do investimento estrangeiro, no Curso de Pós-Graduação Stricto Sensu,
Alvarez destaca aspecto positivo no regime dos BITs, apontando que teria promovido a despolitização do setor, problema presente quando era dispensado o tratamento diplomático, em que se faziam valer os interesses do Estado, em última instância, já que os negociantes os representavam. ${ }^{31}$ Desse modo, afirma que a inibição de "tratamento oportunista", por parte do Estado hospedeiro, teria sido fator importante na promoção do tratamento justo e equilibrado do investidor, sinalizando igualmente o comprometimento do Estado hospedeiro para com a recepção do investimento. ${ }^{32}$

No entanto, não se pode olvidar que o tratamento por essa via acabou ficando conhecido por um regime protetivo do investidor. Alerta Guzman, nesse sentido, que, relativamente a países em desenvolvimento, os riscos decorrentes da assinatura de BITs seriam maiores do que, por exemplo, simplesmente seguir as normas de direito costumeiro internacional. Em se tratando de atrativo de investimento, em determinados casos, o investidor recebe tal proteção que as vantagens e os benefícios auferidos pelo Estado hospedeiro na relação poderão chegar a zero.

Inexiste, no preâmbulo dos BITs, qualquer previsão em torno do incentivo ao desenvolvimento econômico dos Estados hospedeiros, restando claros seus reais objetivos. Ao contrário, os BITs acabam por retirar a flexibilidade do país no que toca, por exemplo, à edição de políticas regulatórias. Diante de disposições como aquelas constantes das cláusulas de estabilização, ${ }^{33} \mathrm{O}$ país fica "engessado", não só para proceder a mudanças que viessem a prejudicar eventualmente as empresas multinacionais, mas também com relação à edição de políticas que poderiam vir a ser benéficas para si, e que são restringidas em razão dos direitos garantidos ao investidor. $^{34}$

No tocante ao mecanismo de solução de disputas

da Universidade Federal do Rio Grande do Sul.

31 ALVAREZ, José E. The Public International Law Regime Governing International Investment. Recueil des cours, v. 344. Pocketbooks of the Hague Academy of International Law, 2009.

32 GUZMAN, Andrew T. "Why LDCs Sign Treaties That Hurt Them: Explaining the Popularity of Bilateral Investment Treaties", 38 Virginia Journal of International Law, 639, 1998.

33 UNCTAD. Course on Dispute Settlement, 2006. Disponível em: $<$ http://r0.unctad.org/disputesettlement/course.htm>. Acesso em: 11 jan. 2013. p. 15

34 Notas do curso ministrado pelo prof. Fábio Morosini, no $2^{\circ}$ semestre de 2012, sobre Regulação do Comércio Internacional e do investimento estrangeiro, no Curso de Pós-Graduação Stricto Sensu, da Universidade Federal do Rio Grande do Sul. 
utilizado, cabe anotar que o mecanismo arbitral de solução de controvérsias para investimentos aplicado aos BITs difere do sistema formal da OMC em alguns aspectos significativos. Menciona-se aqui, primeiramente, a ausência de qualquer mecanismo de recurso da decisão arbitral proferida no painel instaurado, sendo, portanto, única e última. Em segundo lugar, difere do mecanismo usado na solução de disputas da OMC na medida em que qualquer parte pode aceder ao órgão para levar um caso ao seu conhecimento, ao passo que, no seio da OMC, somente governos podem levar demandas ao conhecimento do órgão de resolução de controvérsias.

Nas regras hoje existentes para regulação das relações de investimento, o mecanismo de solução de controvérsias aplicado aos casos entre partes celebrantes de BITs nas disputas envolvendo investimento, a executoriedade da decisão dá-se sob a égide de dois instrumentos: da Convenção de Nova Iorque, de 1958, sobre o Reconhecimento e a Execução de Decisões Arbitrais Estrangeiras; ou da Convenção de Washington de 1968, sobre Resolução de Disputas Internacionais de Investimento, sendo pequenas as diferenças existentes no que toca ao regramento oferecido pelos dois instrumentos. Os órgãos encarregados de conduzir a arbitragem são o Centro para Resolução de Controvérsias sobre Investimento (ICSID) e a Comissão das Nações Unidas para o Direito do Comércio Internacional (UNICITRAL). ${ }^{35}$

Assim, as partes celebrantes do BIT terão a faculdade de escolher, fundadas sobre as previsões constantes do tratado, entre os mecanismos disponíveis, ocorrendo, no mais das vezes, a resolução por câmaras arbitrais ad hoc, de acordo com regras aplicáveis, também escolhidas. O sistema dos BITs acaba por atribuir poder tanto material quanto de interpretação às cortes arbitrais, já que, enquanto as regras aplicáveis diferirem segundo o órgão eleito, não se pode ter uma provisão universal para todas as demandas, prevalecendo o posicionamento deste órgão. As consequências de tal julgamento são em regra bastante sérias e de alta repercussão na realidade interna.

Para melhor compreensão do sistema, optou-se por ilustrar aqui o funcionamento da corte arbitral da ICSID, órgão arbitral que recebe maior volume de demandas nesta seara atualmente. Criada em 1965 por decisão

35 GRAHME F., Thompson. The constitutionalization of the global corporate sphere? Oxford: Oxford University Press, 2012. Capítulo 5, p. 18. do Banco Mundial, ${ }^{36}$ como resultado do tratado multilateral para eliminação dos impedimentos ao livre fluxo internacional de investimentos privados, reuniu, no ano de 2011, 157 Estados signatários (ainda que, destes, apenas 147 sejam formalmente Estados contratantes, tendo completado o procedimento de depósito de seus instrumentos de ratificação, aceitação e aprovação da ICSID). ${ }^{37}$

O ICSID é parte da rede formada por outras organizações ligadas à temática do investimento estrangeiro, dentre as quais se nomeiam a UNCTAD, a UNICITRAL e a OCDE, e também a outros órgãos privados envolvidos no trabalho, constituindo todos, juntamente com os responsáveis pela instrumentalização e desenvolvimento do próprio regime dos BITs. ${ }^{38}$

Sua estrutura é formada por um Conselho Administrativo e por um Secretariado. ${ }^{39} \mathrm{O}$ presidente do Banco Mundial é o Presidente ex-officio do Conselho Administrativo do ICSID, o que evidencia sua íntima ligação com aquele órgão, refletida, por exemplo, nos encontros do Conselho, que se reúne uma vez por ano e cuja data coincide com a do encontro anual do Banco Mundial e do Fundo Monetário Internacional, bem como na relação existente entre o Banco Mundial e a ICSID no que toca à cobertura dos custos administrativos do Conselho e do Secretariado (ainda que estas sejam despesas já abrangidas pelos valores pagos pelas partes da controvérsia).

O Conselho é composto por um representante de cada nação signatária da Convenção e tem como funções precípuas: a eleição do Secretário-Geral e do Deputado Secretário-Geral; a adoção de regulamentos e de regras para instauração e condução dos procedimentos arbitrais; a adoção do orçamento do Centro; e a aprova-

36 Questionável a imparcialidade da corte desde então, tendo em conta que muito provavelmente levará em consideração os princípios que regem as instituições de sua formação e os interesses dos Estados a elas pertencentes, independentemente da ótica sob a qual se esteja estudando.

37 GRAHME F., Thompson. The constitutionalization of the global corporate sphere? Oxford: Oxford University Press, 2012. Capítulo 5, p. 18.

38 GRAHME F., Thompson. The constitutionalization of the global corporate sphere? Oxford: Oxford University Press, 2012. Capítulo 5, p. 20.

${ }^{39}$ ICSID Website. Disponível em: <https://icsid.worldbank.org/ ICSID $/$ FrontServlet? requestType $=$ CasesRH\&action Val $=$ RightFra me\&FromPage $=$ Organization $\% 20$ and $\% 20$ Structure $\&$ pageName $=$ Organization>. Acesso em: 11 jan. 2013 
ção do Relatório Anual sobre sua atuação. ${ }^{40}$ Já o Secretariado é o órgão responsável por conduzir a atividade diária, dando suporte ao Conselho no que for necessário e, sobretudo, organizando os painéis de arbitragem e conciliação. Mantém o Painel de Conciliadores e Árbitros, para o qual cada Estado contratante deve designar quatro pessoas, e o Presidente do Conselho Administrativo, dez pessoas.

Seu procedimento de painel é formado por três árbitros, no mais das vezes (um indicado por cada parte e um que preside o painel, apontado pelo consenso das partes ou por indicação dos outros dois árbitros). Anota-se aqui que, dos 32 casos levados ao ICSID em 2011, 25 deles eram resultado de disputas originadas de BITs, os outros 7 tendo sido provenientes de procedimentos arbitrais domésticos e internacionais.

Não é o Centro em si que faz a arbitragem ou a conciliação, mas proporciona todo o aparato institucional e a estrutura processual para as Comissões Independentes de Conciliação, tribunais arbitrais e Comitês ad hoc, constituídos em cada caso para solução da controvérsia. Dois conjuntos de regras processuais regem o início e a condução do caso: a Convenção, Regulamentos e Regras Adicionais de Instalação, aplicáveis, seja a disputas entre investidores privados e Estados contratantes, seja a investidores privados e Estados não contratantes. $\mathrm{O}$ Centro também julga, embora com menor frequência, demandas contratuais e demandas questionando a legislação doméstica de investimento e as disposições da UNICITRAL, cujo procedimento se assemelha, guardadas algumas diferenças pouco significativas. ${ }^{41}$

A análise do regime dos BITs e do mecanismo de solução de controvérsias constituído em seu entorno suscita a dúvida se estes tratados formariam ou não uma espécie de regime multilateral de investimentos. Stephan Schill ${ }^{42}$ defende que a grande proliferação de tratados bilaterais e multilaterais de investimento, ao contrário

\footnotetext{
${ }^{40}$ ICSID Website. Disponível em: < https://icsid.worldbank.org/ ICSID $/$ FrontServlet?requestType $=$ CasesRH\&actionVal $=$ RightFra me\&FromPage $=$ Organization $\% 20$ and $\% 20$ Structure\&pageName $=$ Organization>. Acesso em: 11 jan. 2013

${ }^{41}$ GRAHME F., Thompson. The constitutionalization of the global corporate sphere? Oxford: Oxford University Press, 2012. Capítulo 5, p. 19.

42 RIPINSKI, Sergey. Stephan W. Schill. The Multilateralization of International Investment Law - Book Review. European Journal of International Law, v. 22, n. 2, p. 598-602. Oxford: Oxford University Press, 2011. Disponível em: <http://ejil.oxfordjournals.org/content/22/2/598.full.pdf+html>. Acesso em: 11 jan. 2013. p. 4
}

de representar a fragmentariedade do regramento internacional de investimentos, significa o funcionamento de uma estrutura verdadeiramente análoga ao que seria a de um regime multilateral. ${ }^{43}$ Aponta, ainda, que a atuação dos tribunais arbitrais de investimento, ao lado dos Estados, contribuiria para a formação de um direito global do investimento, a partir do estudo de casos individuais.

Em razão da falta de definição precisa do conceito de importantes princípios e padrões, cuja presença reiterada foi constatada na vasta maioria dos BITs até então celebrada e de que são exemplos: o "tratamento justo e equitativo" e definições como a do conteúdo da "plena proteção e segurança", das "expropriações indiretas". Os árbitros são levados a, além de aplicar as disposições dos tratados, interpretar esses termos a fim de preencher seu conteúdo, em torno de quê até então não existe consenso formal. ${ }^{44}$ Esta atividade se revela recorrente nas arbitragens de investimento e desperta olhares críticos, tanto positivos quanto negativos, o que será analisado mais adiante no decorrer deste estudo.

Considerando que essas imprecisões se fazem presentes, senão em todos, na vasta maioria dos BITs, e na postura adotada nos painéis arbitrais de investimento, Graham sustenta a existência de um corpo global de direito internacional do investimento, em razão desta estrutura argumentativa dos tribunais arbitrais. ${ }^{45}$ Entretanto, a ausência de atributos essenciais de um sistema multilateral, tais como um instrumento normativo de base, a unidade de fontes, uma instituição jurídica superior para julgar e assumir todas as disputas e um mecanismo recursal, distancia a atual forma de regulação do investimento de uma possível caracterização como sistema multilateral. ${ }^{46}$

43 SCHILL, Stephan W. The Multilateralization of International Investment Law. Online Proceedings, Working Paper n. 18/08. London: Society of International Economic Law, 2008. Disponível em: <http://www.ssrn.com/link/SIEL-Inaugural-Conference.html>. Acesso em: 11 jan. 2013. p. 5-6 e p. 17 e ss.

44 RIPINSKI, Sergey. Stephan W. Schill. The Multilateralization of International Investment Law - Book Review. European Journal of International Law, v. 22, n. 2, p. 598-602. Oxford: Oxford University Press, 2011. Disponível em: <http://ejil.oxfordjournals.org/content/22/2/598.full.pdf + html>. Acesso em: 11 jan. 2013. p. 3

45 RIPINSKI, Sergey. Stephan W. Schill. The Multilateralization of International Investment Law - Book Review. European Journal of International Law, v. 22, n. 2, p. 598-602. Oxford: Oxford University Press, 2011. Disponível em: <http://ejil.oxfordjournals.org/content/22/2/598.full.pdf + html>. Acesso em: 11 jan. 2013. p. 4 46 RIPINSKI, Sergey. Stephan W. Schill. The Multilateralization of International Investment Law - Book Review. European Journal of 
Gus Van Harten entende que o sistema atual apresenta falhas que se refletem, mormente, a partir do déficit democrático, decorrente da ausência de uma base constitucional capaz de promover uma reflexão princiopiológica em torno dos princípios da legalidade, transparência, responsabilidade, participação processual, proporcionalidade, entre outros. Em resposta, apresenta como solução a criação de uma corte única internacional que se ocupe dos casos de investimento estrangeiro. ${ }^{47}$ Afirma o autor que o procedimento arbitral existente carece de imparcialidade, devendo ser substituído por um sistema que tenha como centro uma Corte Internacional de Investimento. ${ }^{48}$

Entretanto, não é somente por essas razões que se acredita que essa visão não mereça prosperar. Tendo em vista que uma Corte internacional depende de um tratado internacional, cai por terra a proposta, já que tal instrumento não existe até o momento no campo do investimento estrangeiro direto, apesar do conhecido histórico de tentativas para criá-lo - todas, porém, até então frustradas.

Independentemente da forma pela qual essa regulação deva ocorrer, aponta-se, invariavelmente, para a necessidade de equilibrar a atividade dos tribunais arbitrais de investimento, a fim de que sua questionada tendência a beneficiar o investidor, foco de grande parte da crítica, seja eliminada para o exercício de um julgamento mais justo e menos tendencioso. $\mathrm{O}$ desequilíbrio na satisfação dos interesses legítimos de cada uma das partes retira a legitimidade do sistema. Deve haver ra-

International Law, v. 22, n. 2, p. 598-602. Oxford: Oxford University Press, 2011. Disponível em: <http://ejil.oxfordjournals.org/content/22/2/598.full.pdf + html>. Acesso em: 11 jan. 2013. p. 4

47 VAN HARTEN, Gus. Investment Treaty Arbitration, Procedural Fairness, and the Rule of Law. Draft forthcoming. In SCHILL (Ed.). International Investment Law and Comparative Public Law. Oxford: Oxford University Press, 2010. Disponível em: <http://papers.ssrn. com/sol3/papers.cfm?abstract_id=1658523>. Acesso em: 11 jan. 2013. VAN HARTEN, Gus. A Case for an Internaional Investment Court. Society for International Economic Law. Working Paper n. 22/2008. Disponível em: <http://www.ssrn.com/link/SIEL-Inaugural-Conference.html>. Acesso em: 11 jan. 2013 e <http://papers.ssrn.com/sol3/ papers.cfm?abstract_id $=1153424>$; sobre a arquitetura do sistema, ver: VAN HARTEN, Gus. Private Authority and Transnational Governance: The Contours of the International System of Investor Protection. 12 Review of Int l Political Economy. 600, 2005. Disponível em: $<$ http://papers.ssrn.com/sol3/papers.cfm?abstract_id=1468690>. Acesso em: 11 jan. 2013.

48 VAN HARTEN, Gus. A Case for an Internaional Investment Court. Society for International Economic Law. Working Paper n. 22/2008. Disponível em: <http://www.ssrn.com/link/SIEL-Inaugural-Conference.html>. Acesso em: 11 fev. 2013. p. 21-29. zoabilidade para que sejam atendidos, de forma equilibrada, interesses públicos e privados. Entretanto, essa atitude requereria a adoção de uma orientação para a implementação de mudanças.

O aumento dos fluxos de investimento, seguido da proliferação dos BITs e da celebração de numerosos tratados multilaterais de investimento, somados ao emprego de mecanismos de solução de controvérsias alternativos, reclama por uma governança ${ }^{49}$ capaz de promover a correta interação entre Direito e Política na regulação do investimento estrangeiro direto. A carência de uma forma de governança no plano global capaz de suprir as demandas hoje identificadas no plano transnacional instigou o desenvolvimento de uma nova proposta de governança: ${ }^{50}$ a do Direito Administrativo Global.

A importância crescente dos atores não estatais na regulamentação internacional provocou o deslocamento dos centros decisórios e regulatórios para a esfera global. A tendência recente de interação em contínuo entre a regulamentação internacional e a doméstica impulsionou a formação de redes intergovernamentais de cooperação, tendo a partir daí emergido o Direito Administrativo Global como uma nova visão deste contexto, constituindo-se uma das lógicas que permeiam

49 O conceito de governança está presente nas mais diversas esferas de relacionamento e corresponde aos arcabouços por meio dos quais os indivíduos e/ou instituições se articulam visando a lidar com questões comuns. No plano transnacional, por governança, entende-se a atuação do governo ou de autoridades responsáveis em uma determinada esfera na forma de conduzir, fazendo uso de suas instituições, o universo em que atua. MAGNOTTA, Fernanda Petená. Multipolaridade e multilateralismo: o G20 e a relação entre poder e governança no século XXI. In: ENCONTRO NACIONAL ABRI 2011, 3., 2011, São Paulo. Associação Brasileira de Relações Internacionais, Instituto de Relações Internacionais - USP. Disponível em: <http://www.proceedings.scielo.br/scielo. php?script=sci_arttext\&pid=MSC0000000122011000200010\&lng $=\mathrm{en} \& \mathrm{nrm}=\mathrm{abn}>$. Acesso em: 22 maio 2013. Apud KEOHANE, Robert O.; NYE, Joseph S. Democracy, Accountability and Global Governance. June 27, 2001. e FERREIRA, Luciano Vaz; MOROSINI, Fábio Costa. As Consequências da Corrupção no Fluxo Transnacional de Investimento Estrangeiro Direto: Estudo Preliminar. In: SEMINÁRIO BRASILEIRO DE ESTUDOS ESTRATÉGICOS INTERNACIONAIS SEBREEI: Integração Regional e Cooperação Sul-Sul no Século XXI. 2012, Porto Alegre. Anais... Porto Alegre, 2012. p. 387-388.

50 Outros exemplos de propostas de governança seriam o constitucionalismo e a estratégia chamada "multi-level". Ver: SANCHEZ, Michelle Ratton. The Global Administrative Law Project: a review from Brazil. In: HAUSER GLOBALIZATION COLLOQUIUM FALL 2008: Global Governance and Legal Theory. NYU Law School: New York, 2008. Disponível em: <http://www.iilj.org/ courses/documents/Sanchez-GALProjectReviewfromBrazil.pdf $>$. Acesso em: 22 maio 2013. p. 7. 
a regulamentação do sistema econômico internacional nos seus diversos âmbitos.

No domínio do regime de investimento, o Direito Administrativo Global aparece a partir justamente dessa atividade regulatória desempenhada pelos tribunais arbitrais, ligados especialmente ao regime dos BITs. A promoção do bem-estar social, do desenvolvimento humano e da sustentabilidade ambiental, e a proteção dos bens que estariam sendo afetados pela sistemática até então vigente deverão nortear este estudo. Busca-se, diante da inserção dos tribunais arbitrais como parte da estrutura de governança do investimento, fazer com que seu trabalho auxilie a constituir e a melhor desenhar o espaço administrativo global.

Acredita-se que, por meio da aplicação dos princípios do Direito Administrativo Global mediante esses mecanismos arbitrais de tomada de decisão, seus pontos nevrálgicos possam ser superados, sobre um fundamento normativo mais sólido. ${ }^{51} \mathrm{O}$ Direito Administrativo Global é responsável pelo estudo de uma estrutura que busca suprir as necessidades verificadas no atual regime de investimento, propondo uma dinâmica capaz de responder às necessidades recorrentes dos atores deste cenário, e cuja apreciação é indispensável neste estágio em que se buscam respostas efetivas para a regulação do investimento estrangeiro.

\section{O DESAFio dA REgULAÇÃO do INVESTIMENTO ESTRANGEIRO DIRETO E OS FUNDAMENTOS DO DI- REITO ADMINISTRATIVO GLOBAL}

\subsection{A emergência do Direito Administrativo Glo- bal}

A crescente interdependência entre as atuações estatais internas e as internacionais evidenciou a necessidade de sistematização de um Direito Administrativo Global..$^{52}$ A temática celebra o desenvolvimento de redes transnacionais, desde aquelas operantes junto às bu-

\footnotetext{
51 ALVAREZ, José E. The Public International Law Regime Governing International Investment. Recueil des cours, v. 344. Pocketbooks of the Hague Academy of International Law, 2009. p. 252.

52 CUNHA, Bruno Santos. Resenha: O direito administrativo sem Estado: crise ou fim de um paradigma? Revista Digital de Direito Público, v. 1. 1, n. 1, p. 242-244, 2012. Disponível em: <mmw.direitorp.usp. br/periodicos $>$. Acesso em: 22 maio 2013. p. 244.
}

rocracias governamentais (do que seria um exemplo os presidentes dos bancos centrais do Comitê de Basileia) até as redes de comunicação transnacional entre juízes nacionais e internacionais, sugerindo que o liberalismo e a democracia seriam características de Estados abertos a esta forma que potencialmente induziria maior observância ao direito internacional. ${ }^{53}$

Seu estudo se desenvolve partindo da premissa do rompimento das fronteiras estatais do Direito Administrativo. Luís Filipe Colaço Antunes ${ }^{54}$ considera o Direito Administrativo Global uma "fronteira-desafio" do movimento que aponta para a tendência de evolução do Direito Administrativo sob novos formatos. Indica que, apoiado sobre uma teoria geral do Direito Administrativo, busca o seu desenvolvimento na esfera global a par do Estado, estando a caminhar da mesma forma que o Direito Administrativo Europeu iniciou sua afirmação na Europa, "com as influências principais a virem de baixo para cima", ou seja, dos ordenamentos administrativos nacionais. ${ }^{55}$

Sua origem remonta ao Projeto elaborado a partir do movimento nascido na Faculdade de Direito da Universidade de Nova Iorque, conduzido por Benedict Kingsbury, Richard Stewart e Nico Kirsch, ${ }^{56}$ que aponta uma vastidão de regimes internacionais como originadores do Global Administrative Law, segundo o qual a ação administrativa global se daria como elaboração de regras, julgamentos e decisões fora da esfera tradicional do direito internacional, aquela constituída a partir da celebração de tratados e conduzida por instituições formais de direito internacional público.

Consiste, ao contrário, no exercício da governança administrativa na área por meio da atividade de organizações internacionais formais, da ação coletiva desen-

\footnotetext{
53 ALVAREZ, José E. The Public International Law Regime Governing International Investment. Recueil des cours, v. 344. Pocketbooks of the Hague Academy of International Law, 2009. p. 329

54 CUNHA, Bruno Santos. Resenha: O direito administrativo sem Estado: crise ou fim de um paradigma? Revista Digital de Direito Público, v. 1. 1, n. 1, p. 242-244, 2012. Disponível em: <mmw.direitorp.usp. br/periodicos $>$. Acesso em: 22 maio 2013. p. 244.

55 CUNHA, Bruno Santos. Resenha: O direito administrativo sem Estado: crise ou fim de um paradigma? Revista Digital de Direito Público, v. 1. 1, n. 1, p. 242-244, 2012. Disponível em: <mwn.direitorp.usp. br/periodicos $>$. Acesso em: 22 maio 2013. p. 243.

56 KINGSBURY, Benedict; KIRSCH, Nico; STEWART, Richard B. The Emergence of Global Administrative Law. Global Administrative Law Series. IILJ Working Paper 2004/1. Disponível em: <http:// www.iilj.org/GAL/documents/TheEmergenceofGlobalAdministrativeLaw. pdf>. Acesso em: 11 jan. 2013. p. 17.
} 
volvida por meio de redes transnacionais envolvendo oficiais nacionais ligados à atividade regulatória do governo, de acordos administrativos distributivos conduzidos por estes oficiais ou por arranjos híbridos, intergovernamentais e privados, ou da ação de instituições privadas com funções regulatórias. ${ }^{57}$

Os exemplos mais densos de regimes regulatórios criados no bojo dessa ação seriam especialmente, no âmbito econômico, o da OCDE, os comitês administrativos da OMC, os comitês do G-7 e do G-8, estruturas de cooperação antitruste e a regulação financeira realizada por órgãos como o FMI, o Comitê de Basileia e a Força-tarefa para Ação financeira da OCDE. Na esfera ambiental, destacam-se as ações de órgãos, como: o Banco Mundial; a OCDE; a OMC; e outras estruturas regulatórias emergentes, como o Mecanismo para o Desenvolvimento Limpo do Protocolo de Kyoto. ${ }^{58}$ Já no domínio da segurança, destacam-se as ações do Conselho de Segurança das Nações Unidas, atuando junto aos seus Comitês, como o da regulação da energia nuclear.

São muitas as agências, organizações, órgãos e instituições envolvidos na atividade administrativa global. Há significativas peculiaridades, no tocante ao desempenho desta tarefa, nesse contexto. A capacidade de ingerência na atividade regulatória doméstica por meio dessas instituições é característica preponderante do sistema. A atividade das cortes internacionais, como do Órgão de Apelação da OMC, e dos tribunais arbitrais nas disputas de investimento é exemplo do exercício da administração global com ampla ingerência nas questões nacionais, cujas consequências despertam por vezes opiniões divergentes.

Instituições internacionais como aquelas que compõem o sistema de Bretton Woods encontram-se igualmente neste rol: o Banco Mundial e o Fundo Monetário Internacional (FMI), no desenvolvimento de políticas de boa governança, estabelecidas como conselhos ou condições para a concessão de auxílio financeiro a países em desenvolvimento.

57 KINGSBURY, Benedict; KIRSCH, Nico; STEWART, Richard B. The Emergence of Global Administrative Law. Global Administrative Law Series. IILJ Working Paper 2004/1. Disponível em: < http:// www.iilj.org/GAL/documents/TheEmergenceofGlobalAdministrativeLaw. $p d f>$. Acesso em: 11 jan. 2013. p. 7 e ss.

58 KINGSBURY, Benedict; KIRSCH, Nico; STEWART, Richard B. The Emergence of Global Administrative Law. Global Administrative Law Series. IILJ Working Paper 2004/1. Disponível em: <http:/ / www.iilj.org/GAL/documents/TheEmergenceofGlobalAdministrativeLaw. pdf>. Acesso em: 11 jan. 2013. p. 7.
Essas normas e decisões interferem na organização interna e na definição de políticas públicas, abrangendo desde questões relativas ao combate à corrupção, até práticas de maior transparência e garantia processual aos atores do mercado. No caso do FMI, por exemplo, o sistema ganha efetividade, tendo seus padrões implementados e respeitados por estes Estados em razão da necessidade compartilhada por um grande número de países de seu auxílio financeiro.

As regras hoje aplicáveis à disciplina do investimento estrangeiro já se encontram inseridas nessa dinâmica, por meio da atividade regulatória desempenhada pelos tribunais arbitrais de investimento. Entretanto, assim como nas demais áreas, permanece sem resposta uma questão que paira sobre essa nova proposta de modelo de governança global: o déficit de legitimidade democrática. Trata-se de uma consequência natural da ausência de uma base constitucional que dê sustentáculo e fundamento ao modelo proposto, seja qual for sua seara de aplicação.

Em especial, no âmbito do investimento estrangeiro, os questionamentos giram em torno da possibilidade de democratização da atividade dos tribunais arbitrais de investimento por esta via, sobretudo em razão da polêmica proteção excessiva dispensada a atores não estatais, como grandes empresas multinacionais, em detrimento do interesse público, dando azo à formulação de críticas em torno da falta de legitimidade, da dificuldade de responsabilização e da falta de transparência. ${ }^{59}$

A arbitragem de investimento, fundada sobre este novo modelo de governança, constituiria nova proposta para resolução de problemas corriqueiros pelos Estados, dispensando o modelo tradicional construído sobre a burocracia centralizada das instituições internacionais formais.$^{60} \mathrm{O}$ modelo se afasta da concepção tradicional da constituição de instituições internacionais formais fundadas sobre tratados internacionais e apoiadas sobre um único documento desempenhando a função de espinha dorsal de um sistema formal.

59 Em geral KINGSBURY, Benedict, KIRSCH, Nico; STEWART, Richard B., 2004.

60 SLAUGHTER, Anne-Marie. Global Government Networks, Global Information Agencies, and Disaggreagated Democracy. Working Paper n. 18. Cambridge: Harvard Law School, 2001. Disponível em: <http:// papers.ssrn.com $/$ sol3 $/$ papers.cfm?abstract_id $=283976>$. Acesso em: 11 jan. 2013. p. 2-3. 
Após a assinatura de tratados bilaterais de investimento e de acordos de livre comércio, o Estado admite sua submissão a uma forma de supervisão interna, aceitando que suas próprias leis, cortes e agências administrativas se submetam ao juízo baseado em padrões internacionais objetivos, estabelecidos pelos diversos atores e instituições atuantes na matéria, ao invés de estar sob o mando de uma única instituição. ${ }^{61}$

Em sua atuação, os tribunais arbitrais para resolução de disputas de investimento procedem, ainda que de forma indireta, a uma revisão dos atos das agências governamentais apoiando-se sobre os padrões estabelecidos na esfera global, procedendo, portanto, à revisão e ao controle da ação pública nacional de regulação. Van Harten e Loughlin apontam que tal sistema se assemelharia à revisão da atividade administrativa interna, com fulcro de manter as autoridades dentro da legalidade e de dar respostas efetivas aos indivíduos prejudicados pela conduta ilegal do Estado. ${ }^{62}$ As regras constantes dos tratados e acordos de investimento deverão, assim, estar de acordo com as previsões dos regimes internacionais vigentes.

Kingsbury e Schill explicam que, como forma de governança, os mecanismos internacionais de investimento precisariam não apenas ser vistos como meios para promoção do crescimento econômico e do desenvolvimento, mas como ferramenta de promoção da responsabilidade democrática e da participação, no plano global, encarando-os como correspondentes às estruturas do direito administrativo doméstico, para os mesmos fins, acreditando em seu potencial para instigar a boa administração do Estado e a proteção dos direitos e de outros interesses. ${ }^{63}$

\footnotetext{
${ }^{61}$ KINGSBURY, Benedict; SCHILL, Stephan. Investor-State Arbitration as Governance: Fair and Equitable Treatment, Proportionality and the Emerging Global Administrative Law. Public Law and Legal Theory Research Paper Series. Working Paper n. 09-46. New York: New York University School of Law, 2009. Disponível em: < bttp:/ / ssrn.com/abstract=1466980>. Acesso em: 11 jan. 2013.

${ }^{62}$ VAN HARTEN, Gus; LOUGHLIN, Martin. Investment Treaty Arbitration as a Species of Global Administrative Law. European Journal of International Law. V. 17, n. 1. pp. 121-150. Oxford: Oxford University Press, 2006. Disponível em: <http://ejil.oxfordjournals. org/>. Acesso em: 11.01.2013. p. 149.

${ }^{63}$ KINGSBURY, Benedict; SCHILL, Stephan. Investor-State Arbitration as Governance: Fair and Equitable Treatment, Proportionality and the Emerging Global Administrative Law. Public Law and Legal Theory Research Paper Series. Working Paper n. 09-46. New York: New York University School of Law, 2009. Disponível em: <http:/ / ssrn.com/abstract=1466980 >. Acesso em: 11 jan. 2013. p. 131.
}

Conforme apontado, evidencia-se a sobreposição dessas novas proposições trazidas pelo Direito Administrativo Global à estrutura formal antes tomada como padrão para a esfera internacional, em razão das demandas apresentadas pela nova configuração das relações globais, envolvendo maior diversidade de atores em diferentes contextos, seguindo diferentes padrões normativos, nem sempre concentrados em um único instrumento. Surge, no âmbito da solução de controvérsias de investimento, um modelo fundado sobre valores transnacionais, para ser comparado com o modelo clássico de solução de controvérsias, seguido, por exemplo, pela Corte Internacional de Justiça (ICJ) e pela OMC, em que apenas Estados são admitidos como partes.

Trata-se de exemplo de aprofundamento da judicialização e de distanciamento do modelo da proteção diplomática, de modo a prevalecer a rule of law, a aplicação do direito, na regência destas novas relações na seara do investimento. ${ }^{64}$

Em resposta aos críticos que apontam como deficiência do modelo apresentado o déficit democrático no sistema de arbitragem de investimento, propõe-se a introdução de mecanismos de responsabilização, que traria o equivalente ao caráter democrático dado pelo procedimento administrativo e garantia dos direitos processuais, presentes na esfera nacional, para o plano transnacional. ${ }^{65}$ Este mecanismo de responsabilização funciona por meio da instituição de princípios, procedimentos e remédios para o bom funcionamento da administração global. Esta estrutura viria para suprir a ausência no plano da administração global dos elementos responsáveis pela democracia no âmbito doméstico, de que são exemplos a participação processual e um mecanismo revisional. ${ }^{66}$

${ }^{64}$ ALVAREZ, José E. The Public International Law Regime Governing International Investment. Recueil des cours, v. 344. Pocketbooks of the Hague Academy of International Law, 2009. p. 342.

${ }_{65}$ BITENCOURT NETO, Eurico. Direito Administrativo Transnacional. Revista Eletrônica de Direito Administrativo Econômico - REDAE. n. 18, Maio/Jun./Jul. 2009. Salvador. Disponível em: < http://www. direitodoestado.com/revista/REDAE-18-MAIO-2009-EURICOBITENCOURT.pdf> . Acesso em: 22 maio 2013. p. 12.

66 KINGSBURY, Benedict; KIRSCH, Nico; STEWART, Richard B. The Emergence of Global Administrative Law. Global Administrative Law Series. IILJ Working Paper 2004/1. Disponível em: <http:// wmw.iilj.org/GAL/documents/TheEmergenceofGlobalAdministrativeLaw.pdf>. Acesso em: 11 
Pautando-se pelo modelo proposto de Direito Administrativo Global, a normativa do investimento e a forma de solução de controvérsias hoje adotada passariam a se pautar pelos equivalentes de princípios, normas e institutos de direito administrativo domésticos, transpostos, com as devidas adaptações, para o plano global. ${ }^{67}$ Adepta deste modelo, Anne-Marie Slaughter faz uma analogia entre as estruturas de governança encontradas na União Europeia e aquelas hoje identificáveis no plano internacional, especialmente no que se refere à atuação em redes transgovernamentais público-privadas. ${ }^{68}$

Pelo mecanismo de arbitragem investidor-Estado, dá-se ao investidor a oportunidade de desafiar a atividade administrativa do Estado hospedeiro perante tribunais arbitrais internacionais, caso entenda que os direitos que lhe assistem, fundados sobre o BIT celebrado, por exemplo, estão sendo violados. Cresce, portanto, a incidência de decisões provenientes destes tribunais, estendendo limitações tanto de cunho processual quanto de cunho material, na regulação doméstica. ${ }^{69}$

A atividade regulatória desempenhada pelos tribunais arbitrais de investimento passa, portanto, a exercer grande influência também nas esferas nacionais, diante do efeito regulatório exercido sobre a legislação interna, por meio das decisões proferidas. Sua atividade, portanto, deve se pautar pelo objetivo de garantir a introdução de verdadeiros padrões internacionalmente estabelecidos no plano doméstico dos Estados, nomeadamente aqueles que guardam relação com um dos padrões cuja presença é detectada com frequência nos BITs celebrados, qual seja, o do "tratamento justo e equitativo". ${ }^{70}$

\footnotetext{
jan. 2013. p. 15

67 BITENCOURT NETO, Eurico. Direito Administrativo Transnacional. Revista Eletrônica de Direito Administrativo Econômico - REDAE. n. 18, Maio/Jun./Jul. 2009. Salvador. Disponível em: <http://www. direitodoestado.com/revista/REDAE-18-MAIO-2009-EURICOBITENCOURT.pdf $>$. Acesso em: 22 maio 2013. p. 12.

68 SLAUGHTER, Anne-Marie. Global Government Networks, Global Information Agencies, and Disaggreagated Democracy. Working Paper n. 18. Cambridge: Harvard Law School, 2001. Disponível em: <http:// papers.ssrn.com/sol3/papers.cfm?abstract_id=283976>. Acesso em: 11 jan. 2013. p. 3.

${ }^{69}$ KINGSBURY, Benedict; KIRSCH, Nico; STEWART, Richard B. The Emergence of Global Administrative Law. Global Administrative Law Series. IILJ Working Paper 2004/1. Disponível em: <http:/ / www.iilj.org/GAL/documents/TheEmergenceofGlobalAdministrativeLaw. pdf>. Acesso em: 11 jan. 2013. p. 23

${ }_{70}$ A esse respeito: SCHILL, Stephan W. Fair and Equitable Treatment under Investment Treaties as an Embodiment of the Rule of Law. Global Administrative Law Series. IILJ Working Paper 2006/6. Disponível em: <http://www.iilj.org/publications/2006-6Schill.asp>. Acesso
}

Emergem, paralelamente, manifestações quanto à atribuição de poder excessivo ao investidor, por meio do uso desta ferramenta, nem sempre contrabalançada por suficiente representação do interesse público em geral. ${ }^{71}$ Argui-se aqui a transposição de funções por delegação (consolidada na aceitação pelo Estado da instância arbitral para resolução da disputa), originariamente pertencentes ao direito administrativo doméstico (dotado de mecanismos de transparência, participação e revisão), ao direito administrativo global (que não disporia de mecanismos correspondentes, responsáveis pela garantia da devida fiscalização e responsabilização na atividade desempenhada). Aponta-se que esta forma de exercício poderia até vir a inspirar uma forma de evasão à revisão efetiva da esfera doméstica. ${ }^{72}$

São tecidas importantes críticas também em torno da atividade regulatória dos tribunais, destacando-se o ativismo dos árbitros, que dispõem de amplos poderes para análise de proporcionalidade e o uso de outros instrumentos de direito público, em domínios que deveriam ser objeto de deliberação exclusiva das políticas públicas destes, como nas esferas ambiental e de política econômica.

Nesse bojo, a orientação e a formação do árbitro definirão sua postura, ao decidir questões de efetivo interesse público, ao confrontá-las com os interesses dos investidores. ${ }^{73}$ Árbitros de tendência mais comercial terão menos atenção a estas questões, enquanto que árbitros mais preocupados com a judicialização do sistema seguirão a tendência mais formalista das cortes internacionais. No regime do investimento, os laudos arbitrais refletem aspectos políticos e pragmáticos da orientação do árbitro que decide a causa. ${ }^{74}$

em: 22 maio 2013.

${ }^{71}$ KINGSBURY, Benedict; KIRSCH, Nico; STEWART, Richard B. The Emergence of Global Administrative Law. Global Administrative Law Series. IILJ Working Paper 2004/1. Disponível em: < http:// wnw.iilj.org/GAL/documents/TheEmergenceofGlobalAdministrativeLaw. pdf>. Acesso em: 11 jan. 2013. p. 23

${ }_{72}$ KINGSBURY, Benedict; KIRSCH, Nico; STEWART, Richard B. The Emergence of Global Administrative Law. Global Administrative Law Series. IILJ Working Paper 2004/1. Disponível em: < bttp:// www.iilj.org/GAL/documents/TheEmergenceofGlobalAdministrativeLaw. pdf>. Acesso em: 11 jan. 2013. p. 39

73 VAN HARTEN, Gus. A Case for an Internaional Investment Court. Society for International Economic Law. Working Paper n. 22/2008. Disponível em: <http://www.ssrn.com/link/SIEL-Inaugural-Conference.html>. Acesso em: 11 jan. 2013. p. 22.

${ }^{74}$ VAN HARTEN, Gus. Arbitrator Behaviour in Asymmetrical Adjudication: An Empirical Study of Investment Treaty Arbitration. Research Paper Series. Research Paper n. 41/2012. Toronto: Oos- 
A esse respeito, exalta-se a ausência de salvaguardas institucionais de independência, tendo em vista, por exemplo, a inexistência de qualquer vedação a que os árbitros que decidem os casos, indicados por um ou por outro lado, atuem também na condição de advogados, aconselhando, eventualmente, investidores em casos similares, até mesmo simultâneos, de modo que podem, ao mesmo tempo, ser árbitro, em um caso, e estar representando o investidor ou o Estado, como advogado, em outro. Disso resulta uma jurisprudência fraca e informal, potencialmente recheada de conflitos de interesse.

Grahme elenca uma série de razões pelas quais o procedimento arbitral não poderia ser considerado idôneo e compatível com o que se esperaria de um procedimento judicial em uma sociedade democrática, aparecendo, ao contrário, tendencioso, devido ao tráfico de interesses, carente de transparência e de equilíbrio entre as partes da demanda. ${ }^{75}$

No sistema, são ausentes quesitos que seriam essenciais para o exercício de forma idônea e imparcial da atividade arbitral, tais como a promoção da participação processual das minorias atingidas. Fica, assim, sem amparo o público afetado pela adoção ou alteração de políticas públicas no âmbito interno, originadas de decisões arbitrais em disputas de investimento, em que os interesses dos investidores se fizeram preponderantes no julgamento.

Esse tipo de consequência estaria representando uma afronta política à atual forma de solução de controvérsias de investimento. ${ }^{76} \mathrm{~A}$ fundamentação das decisões proferidas é igualmente essencial neste quadro, sendo indispensável nesses casos em que a atividade administrativa global regulatória repercute sobre determi-

gode Hall Law School, 2012. Disponível em: < http://ssrn.com/abstract $=2149207>$. Acesso em: 11 jan. 2013, p. 49; e VAN HARTEN, Gus. A Case for an Internaional Investment Court. Society for International Economic Law. Working Paper n. 22/2008. Disponível em: <http:/ / www.ssrn.com/link/SIEL-Inaugural-Conference.html>. Acesso em: 11 jan. 2013. p. 30.

75 GRAHME F, Thompson. The constitutionalization of the global corporate sphere? Oxford: Oxford University Press, 2012. Capítulo 5, p. 23.

76 KINGSBURY, Benedict; KIRSCH, Nico; STEWART, Richard B. The Emergence of Global Administrative Law. Global Administrative Law Series. IILJ Working Paper 2004/1. Disponível em: < http:/ / www.iilj.org/GAL/documents/TheEmergenceofGlobalAdministrativeLaw. pdf>. Acesso em: 11 jan. 2013. p. 24

77 ALVAREZ, José E. The Public International Law Regime Governing International Investment. Recueil des cours, v. 344. Pocketbooks of the Hague Academy of International Law, 2009. p. 330. nados indivíduos ou minorias. ${ }^{78}$

Igualmente, um procedimento revisional por uma corte ou tribunal independente é essencial neste âmbito. $\mathrm{Na}$ esfera nacional, uma das características mais relevantes do direito administrativo é a de poder ter seus atos submetidos à revisão judicial perante uma corte ou tribunal. Na esfera global, o raciocínio é paralelo: a possibilidade de revisão das decisões proferidas por órgãos da administração global é essencial para sua legitimidade. É o que se reflete, por exemplo, no sistema administrativo vigente na União Europeia, em que órgãos europeus de proteção dos direitos humanos afirmaram repetidas vezes a importância desse direito em relação às decisões administrativas proferidas por órgãos intergovernamentais. $^{79}$

Ainda, a partir de sua definição, como sendo de caráter público ou não, dependerá o futuro da arbitragem de investimento da criação de um sistema de leis, da formação de um corpo jurisprudencial, da dotação de maior transparência ao processo, da promoção do acesso a terceiros ao julgamento e da exigência de completa fundamentação das decisões proferidas. ${ }^{80}$

Proporcionalidade, racionalidade entre meios e fins, emprego de meios menos gravosos figuram entre os padrões materiais que devem nortear a atividade administrativa global. Inexiste ainda um consenso acerca de como deve ser feita a abordagem destas deficiências ligadas à imparcialidade, à transparência e à legitimidade no campo da solução de controvérsias em disputas internacionais de investimento, mas os debates de Direito Administrativo Global buscam respostas a estas questões. ${ }^{81}$

78 KINGSBURY, Benedict; KIRSCH, Nico; STEWART, Richard B. The Emergence of Global Administrative Law. Global Administrative Law Series. IILJ Working Paper 2004/1. Disponível em: < bttp:// www.iilj.org/GAL/documents/TheEmergenceofGlobalAdministrativeLaw. pdf>. Acesso em: 11 jan. 2013. p. 25

79 Trata-se inclusive de direito sustentado pela Convenção Europeia de Direitos Humanos, constante dos artigos 6 e 14.

${ }^{80}$ ALVAREZ, José E. The Public International Law Regime Governing International Investment. Recueil des cours, v. 344. Pocketbooks of the Hague Academy of International Law, 2009. p. 344.

81 A esse respeito, Gus Van Harten e Susan Frank divergem profundamente, entendendo o primeiro que os argumentos empregues por Susan Frank para defesa do funcionamento adequado do sistema são fracos e carentes, em razão de não serem sustentados por dados precisos. Susan Franck, por seu turno, a partir de seu estudo, revela que as decisões arbitrais não são influenciadas em função do nível de desenvolvimento do país, consideração fortemente criticada por Van Harten. A esse respeito: VAN HARTEN, Gus. Fairness and Independence in Investment Arbitration: A Critique of Susan Franck's 
O modelo Direito Administrativo Global propõe vias para uma reforma do sistema, procurando suprir as necessidades existentes e esculpir um sistema em que os problemas ora aventados não mais se façam presentes. As mudanças apresentadas para a solução desses problemas serão o objeto analisado no capítulo seguinte, apresentando-se as conclusões obtidas a partir da evolução do Direito Administrativo Global aplicado ao investimento estrangeiro. A partir da dinâmica institucional proposta, busca-se determinar o que falta ainda para que a governança do Direito Administrativo Global no campo do investimento tenha repercussão positiva tanto para investidores quanto para os atores Estatais.

\subsection{Fundamentos do Direito Administrativo Global aplicados à atividade regulatória do investimento estrangeiro}

No que toca à atividade regulatória do modo de solução de controvérsias aplicado ao investimento estrangeiro atualmente, são formuladas críticas apoiadas sobre o fato de que decisões arbitrais (logo, privadas) proferidas teriam o condão de influenciar de maneira profunda a adoção das políticas internas de um país, o que, em última instância, representaria a delegação a uma junta arbitral do juízo acerca de questões que demandam amplo debate e participação pública, conforme os pilares democráticos, que lhe atribuem legitimidade. ${ }^{82}$ Nessa esteira, afirma-se que o funcionamento desse mecanismo estaria sendo colocado na função de agências revisionais externas da conduta do Estado, o que desperta questões quanto à legitimidade destes órgãos para o desempenho de função análoga. ${ }^{83}$

Diante das críticas tecidas e da problemática apontada relativamente ao sistema arbitral de investimento, surgem em resposta proposições diversas, como o retorno às tentativas de multilateralização do sistema, como proposto por Stephan Schill, ${ }^{84}$ por exemplo, ou de constitucionalização

'Development and Outcomes of Investment Treaty Arbitration'. ITN Quarterly, Dezembro, 2010. Disponível em: <http://www.iisd.org/itn/>. Acesso em: 11 jan. 2013; e FRANCK, Susan. Development and Outcomes of Investment Treaty Arbitration. Harvard International Law Journal, v. 50, n. 2, 2009; Washington \& Lee Legal Public Legal Studies Research Paper Series. Working Paper n. 2009. Disponível em: < http://papers.ssrn.com/sol3/papers. cfm?abstract_id $=1406714>$. Acesso em: 11 jan. 2013.

82 GRAHME F., Thompson. The constitutionalization of the global corporate sphere? Oxford: Oxford University Press, 2012. Capítulo 5, p. 23.

83 KINGSBURY, Benedict; SCHILL, Stephan. Investor-State Arbitration as Governance: Fair and Equitable Treatment, Proportionality and the Emerging Global Administrative Law. Public Law and Legal Theory Research Paper Series. Working Paper n. 09-46. New York: New York University School of Law, 2009. Disponível em: <bttp://ssrn.com/abstract $=1466980>$. Acesso em: 11 jan. 2013. Capítulo IV.

${ }^{84}$ SCHILL, Stephan W. The Multilateralization of International Investment Law. Online Proceedings, Working Paper n. 18/08. London: Society of International Economic Law, 2008. Disponível em: < http://www.ssrn. do sistema, seguindo a lição de Grahme, apontando, nesta medida, que os aspectos materiais seriam uma preocupação preponderante, posição da qual diverge Van Harten, ao entender que as questões procedimentais devem ser o foco da rule of law, mais do que os aspectos materiais.

Van Harten, inclusive, propõe uma corte comercial internacional formal para tratar das relações de investimento, a qual seria composta de juízes internacionais, sem nenhuma tendência comercial, imunes aos conflitos de interesses pelos quais os procedimentos arbitrais se encontrariam hoje contaminados. Tal corte julgaria disputas transfronteiriças e executaria os contratos e regulamentos. A corte seria regida pelos padrões usuais do devido processo legal, primando pela absoluta transparência, e prevendo-se também em seu bojo uma via recursal..$^{85}$

Sinaliza Kingsbury que propostas como a de Van Harten seriam exemplos de uma estratégia do tipo "top-down", ou seja, "de cima para baixo", cuja dinâmica consiste na imposição de um regramento multilateral, estruturado sobre instituições formais de direito internacional, refletindo a concepção tradicional dos sistemas de direito internacional. ${ }^{86}$ No entanto, diante da maré "antiformalização" que hoje se robustece, ${ }^{87}$ a perspectiva de maior rigidez institucional parece se distanciar do momento de sair do papel. Emergem, por outro lado, fundadas sobre a dinâmica do Direito Administrativo Global, propostas para suprir as deficiências apontadas.

São proposições que, partindo-se da realidade verificada em torno do regramento hoje existente para o investimento estrangeiro direto, se mostram próximas daquilo que é viável. Foge-se aqui às propostas anteriormente descritas de multilateralização, de criação de um sistema institucional, seguindo os moldes tradicionais do direito internacional. $\mathrm{O}$ intuito aqui é o de tornar o mecanismo de solução de controvérsias para o investimento estrangeiro direto uma experiência melhor do que o que se observou até hoje a partir da atuação de órgãos formais como a CIJ e a OMC, que, sabe-se, padecem de sérios problemas.

com/link/SIEL-Inaugural-Conference.html>. Acesso em: 11 jan. 2013.

85 VAN HARTEN, Gus. A Case for an Internaional Investment Court. Society for International Economic Law. Working Paper n. 22/2008. Disponível em: $<$ http://www.ssrn.com/link/SIEL-Inaugural-Conference.html>. Acesso em: 11 jan. 2013. p. 21.

86 KINGSBURY, Benedict; KIRSCH, Nico; STEWART, Richard B. The Emergence of Global Administrative Law. Global Administrative Law Series. IILJ Working Paper 2004/1. Disponível em: < bttp:// wmw.iilj.org/GAL/ documents/TheEmergenceofGlobalAdministrativeLaw.pdf>. Acesso em: 11 jan. 2013. p. 43.

87 Tendência ao abandono das instituições formais de direito internacional nas realidades em que há grande diversidade de atores (privados, públicos, híbridos) e cuja normativa aplicável não é única ou uniforme, sendo formada por várias fontes e instrumentos. É o que se constata na realidade de hoje na regulação do investimento estrangeiro direto. 
Para tanto, Stephan Schill aporta ao estudo do Direito Administrativo Global contribuição significativa ao propor o assentamento da estrutura de solução de controvérsias de investimentos hoje vigente sobre o princípio do "tratamento justo e equitativo". ${ }^{88}$ Nessa esteira, esta estrutura para solução de controvérsias em matéria de investimento deveria ser vista como parte de um tipo de administração consistente em uma rede flexível que, por meio da produção crescente de um corpo jurisprudencial relativamente homogêneo na interpretação de certos termos de direito administrativo que aparecem em quase todos os BITs, ${ }^{89}$ estaria funcionando de maneira eficaz como um "estabelecedor global de padrões" no campo do Direito Administrativo Global para o investimento estrangeiro. ${ }^{90}$

Alvarez e Khamsi, contudo, posicionam-se do lado contrário dessa corrente que aceita esta tendência de formação de um corpo administrativo jurisprudencial nesta seara. Argumentaram, exemplificando com casos concretos, que não se verifica necessariamente uma tendência de uniformidade interpretativa quando se está diante de situações com circunstâncias similares emergentes sob a égide de um mesmo tratado. Ilustram este posicionamento com caso estudado em sua análise, em que não foi sequer apreciado posicionamento anterior, sendo os casos muito semelhantes em que, contudo, foram proferidas decisões antagônicas. ${ }^{91}$

Arguem que, na dinâmica do investimento estrangeiro, os árbitros são escolhidos caso a caso, sem nenhuma vinculação no sentido de seguir ou tomar conhecimento de outros precedentes. Deste posicionamento, compartilham, sobretudo, estudiosos do campo da arbitragem comercial internacional.

\footnotetext{
88 SCHILL, Stephan W. Fair and Equitable Treatment under Investment Treaties as an Embodiment of the Rule of Law. Global Administrative Law Series. IILJ Working Paper 2006/6. Disponível em: <http://www.iilj.org/ publications/2006-6Schill.asp>. Acesso em: 22 maio 2013.

89 O uso crescente de "modelos" nesse campo resultou em uma verdadeira homogeneidade desses tratados. Esta atividade torna-se ainda mais importante diante do fato de que considerável número de BITs passou a se referir a estes padrões como sendo parte de um direito internacional costumeiro geral.

90 MACDONALD, Euan. GAL and the nature of Bilateral Investment Treaty (BIT) tribunals. Global Administrative Law - A blog dedicated to the continued development of the global administrative law (GAL) project: highlighting new events and publications and providing a forum for discussion and debate. Disponível em: <http://globaladminlaw.blogspot.com.br/2008/03/gal-and-natureof-bilateral-investment.html>. Acesso em: 22 maio 2013.

91 ALVAREZ, José E.; KHAMSI, Kathryn. The Argentine Crisis and Foreign Investors: A Glimpse into the Heart of the Investment Regime. Global Administrative Law Series. IILJ Working Paper 2006/6. Disponível em: < bttp:/ / wmw. iilj.org/publications/2008-5 Alvarez-Khamsi.asp>. Acesso em: 22 maio 2013 e MACDONALD, Euan. GAL and the nature of Bilateral Investment Treaty (BIT) tribunals. Global Administrative Law - A blog dedicated to the continued development of the global administrative law (GAL) project: highlighting new events and publications and providing a forum for discussion and debate. Disponível em: <http://globaladminlaw.blogspot.com.br/2008/03/gal-and-natureof-bilateral-investment.html>. Acesso em: 22 maio 2013.
}

Alvarez, contudo, destacou que tal conduta de total desconsideração do precedente anterior despertou ferrenhas críticas à ocasião do julgamento por aqueles que trabalham com arbitragem de investimento.

Esse tipo de exemplo seria capaz de enfraquecer a teoria de Schill, segundo a qual haveria uma tendência à formação de uma rede flexível de administração por essas cortes arbitrais, fundada sobre uma possível harmonia interpretativa. Daí também emergem questões quanto à natureza desses órgãos de resolução de controvérsias de investimento emergentes de BITs, se deveriam ou não ser compreendidos como arbitragens comerciais (e portanto puramente privadas) ou se seriam de uma natureza específica, a pressupor certo grau de "publicização", o que, assim, tornaria adequada a aplicação de alguma noção em termos de precedente e ainda, possivelmente, outros mecanismos do direito administrativo, como devido processo legal e mecanismos de responsabilização institucional. ${ }^{92}$

Nessa esteira de que seria inevitável certo grau de publicização nessa esfera, a intenção de Schill é a de que, por meio do Direito Administrativo Global, garanta-se que a atuação dos órgãos de governança domésticos, regionais e globais que exercem poderes de relevância pública esteja enquadrada nos padrões de transparência, consulta, participação, racionalidade e legalidade e que haja revisão efetiva e independente das regras e decisões destes órgãos. O emprego do termo "global" decorre justamente desse envolvimento das esferas tanto nacional quanto internacional e, também, de atores e reguladores privados, híbridos, arranjos institucionais informais, que atuam em conjunto com instituições formais, além de ter em conta o fato da variedade de fontes normativas e de suas práticas, tanto transnacionais quanto internacionais. ${ }^{93}$

Esses processos de tomada de decisão estão intimamente relacionados ao cumprimento dos padrões estabelecidos internacionalmente por esses diversos órgãos referidos e têm considerável impacto especialmente nos países em desenvolvimento, muito dependentes do investimento estrangeiro e da assistência externa, e com frequência carecem de experti-

\footnotetext{
92 ALVAREZ, José E.; KHAMSI, Kathryn. The Argentine Crisis and Foreign Investors: A Glimpse into the Heart of the Investment Regime. Global Administrative Law Series. IILJ Working Paper 2006/6. Disponível em: < bttp:/ / mwn.iilj.org/publications/2008-5 Alvarez-Khamsi.asp>. Acesso em: 22 maio 2013 MACDONALD, Euan. GAL and the nature of Bilateral Investment Treaty (BIT) tribunals. Global Administrative Law - A blog dedicated to the continued development of the global administrative law (GAL) project: highlighting new events and publications and providing a forum for discussion and debate. Disponível em: <http://globaladminlaw.blogspot.com.br/2008/03/gal-and-natureof-bilateral-investment.html>. Acesso em: 22 maio 2013.

93 KINGSBURY, Benedict; STEWART, Richrd B. Perspectives on the Development of Global Administrative Law in Latin America. El nuevo derecho administrativo global en América Latina. Buenos Aires: Rap, 2009. Disponível em: <http://iilj.org/GAL/documents/GALBAbook. Introduction.pdf $>$. Acesso em: 22 maio 2013. p. 12
} 
se e de estrutura institucional para que consigam influenciar, desviar ou lidar com estas disposições. Kingsbury e Schill defendem que os tribunais arbitrais de investimento deveriam ser encarados como instrumentos de exercício de poder no espaço administrativo global..$^{94}$

O Direito Administrativo Global deve, nesse bojo, tentar reverter a criticada tendência de favorecimento do investidor ou do Estado, por meio da inserção de padrões a serem seguidos de transparência, responsabilização institucional, consulta, racionalidade e legalidade. Em suma, aplicando os princípios do DAG na atividade regulatória exercida a partir do mecanismo de solução de controvérsias, de modo a reduzir esse tipo de questionamento em torno de sua parcialidade.

Afirmam que, ao definir padrões de conduta para o Estado diante dos investidores estrangeiros, definindo, por exemplo, o que seria administração imprópria ou violação do devido processo legal em face do tratamento justo e equitativo, pode estar exercendo influência não só sobre o comportamento daquele Estado, e também de outros Estados, quando em face de situações semelhantes, mas também sobre a própria conduta de outros tribunais arbitrais. São, portanto, considerados atores de governança, e não apenas julgadores ou tomadores de decisão em casos singulares. ${ }^{95}$

Em resposta, vêm à baila questionamentos dos críticos com relação à legitimidade da atividade regulatória desses tribunais. Schill defende que, aplicando-se o critério do Direito Administrativo Global aos tribunais arbitrais e estes em seu trabalho, seria possível melhorar este problema de legitimidade. Santiago Montt ${ }^{96}$ afirma que esta atividade administrativa global exercida pelos tribunais poderá ser positiva quando aplicados os princípios das doutrinas Bello e Calvo às realidades latino-americanas, no sentido de tratar igualmente nacionais e estrangeiros, em questões referentes à propriedade e à proteção dos direitos econômicos e processuais.

O problema que demanda análise mais apurada nessa seara diz, com a vaga definição das garantias-padrão pelos

\footnotetext{
94 KINGSBURY, Benedict; STEWART, Richrd B. Perspectives on the Development of Global Administrative Law in Latin America. El nuevo derecho administrativo global en América Latina. Buenos Aires: Rap, 2009. Disponível em: < http://iilj.org/GAL/documents/GALBAbook. Introduction.pdf $>$. Acesso em: 22 maio 2013. p. 16.

95 KINGSBURY, Benedict; STEWART, Richrd B. Perspectives on the Development of Global Administrative Law in Latin America. El nuevo derecho administrativo global en América Latina. Buenos Aires: Rap, 2009. Disponível em: < http://iilj.org/GAL/documents/GALBAbook. Introduction.pdf $>$. Acesso em: 22 maio 2013. p. 16.

96 MONTT, Santiago. What international investment law and Latin America can and should demand from each other. Updating the Bello/ Calvo doctrine in the BIT generation. Revista Argentina del Regimen de la Administración Publica. Rap: Buenos Aires, 2007. Disponível em: <http:// www.iilj.org/GAL/documents/montt.pdf>. Acesso em: 22 maio 2013.
}

tratados internacionais de investimento, o que suscita uma percepção de que a interpretação dos tribunais arbitrais responsáveis pela solução de controvérsias emergentes desses tratados seria imprevisível, correndo ainda o risco de ser inconsistente e por vezes contraditória. ${ }^{97}$

Emergem daí os comentários quanto à crise de legitimidade na arbitragem de investimento. O princípio do tratamento justo e equitativo é trazido à apreciação na medida em que abrange uma diversidade de garantias e direitos, dentre os quais estariam compreendidos, conforme enumerado por Schill: estabilidade, previsibilidade e consistência; legalidade; proteção da confiança e de expectativas legítimas; devido processo administrativo e negativa de prestação jurisdicional; proteção contra arbitrariedade e discriminação; transparência, razoabilidade e proporcionalidade..$^{98}$

Seria essa a cláusula que permitiria adentrar de maneira mais profunda no domínio reservado do Estado hospedeiro, constituindo um dos conceitos-chaves da governança das relações entre investidores e Estados, fazendo-se presente na vasta maioria dos BITs e também em tratados multilaterais de investimento, como é o caso do NAFTA (princípio constante do art. 1105 (1) do referido acordo) e do ECR (artigo 10(1) do tratado).

Diante da vaga conceituação desse padrão, contudo, os tribunais arbitrais de investimento são confrontados com a importante tarefa de preenchê-lo de conteúdo normativo, de acordo com o caso em que é aplicado. Para o autor, a construção do conteúdo normativo deste princípio seria exemplo do exercício da atividade administrativa global pelos tribunais arbitrais de investimento que, deparando-se com reiteradas questões emergentes dos tratados bilaterais de investimento, acabariam por consolidar um preenchimento adequado à normativa vaga daquele padrão estudado do tratamento justo e equitativo, definindo seus elementos. ${ }^{99}$

Stephan Schill procura demonstrar que a jurisprudência dos tribunais de investimento sobre o tratamento justo e equitativo pode ser resumida em um conceito essencialmente institucional e processual da aplicação do direito, que encontra correspondência nos principais sistemas jurídicos internos das democracias liberais e argumenta que tal enten-

\footnotetext{
${ }^{97}$ SCHILL, Stephan W. Fair and Equitable Treatment under Investment Treaties as an Embodiment of the Rule of Law. Global Administrative Law Series. IILJ Working Paper 2006/6. Disponível em: <http://www.iilj.org/ publications/2006-6Schill.asp>. Acesso em: 22 maio 2013. p. 2.

98 SCHILL, Stephan W. Fair and Equitable Treatment under Investment Treaties as an Embodiment of the Rule of Law. Global Administrative Law Series. IILJ Working Paper 2006/6. Disponível em: <http://www.iilj.org/ publications/2006-6Schill.asp>. Acesso em: 22 maio 2013. p. 11.

99 SCHILL, Stephan W. Fair and Equitable Treatment under Investment Treaties as an Embodiment of the Rule of Law. Global Administrative Law Series. IILJ Working Paper 2006/6. Disponível em: <http://www.iilj.org/ publications/2006-6Schill.asp>. Acesso em: 22 maio 2013. p. 9.
} 
dimento pode ser normativamente fundamentado no objetivo de tratados internacionais de investimento.

Buscam-se previsibilidade e uniformidade interpretativa em torno desse padrão que, como visto, tem diferentes vieses e oferece ampla capacidade de penetração no que seria chamado de "domínio reservado" do Estado hospedeiro, devendo, por esta razão, ser alvo de apurada análise no intuito de afastar possíveis decisões arbitrárias neste campo. Falta ainda, porém, clareza quanto à definição de seu conteúdo normativo, apesar de sua frequente aplicação. Disso decorrem questionamentos em torno da responsabilização institucional dos tribunais arbitrais de investimento e da legitimidade da jurisprudência por estes construída. A pesquisa desenvolvida por Stephan Schill busca compreender o tratamento justo e equitativo como uma encarnação do Estado de Direito.

Tendo identificado certos sub-elementos desse padrão a partir da atividade dos tribunais arbitrais de investimento, o autor defende a ideia de que estes elementos podem ser compreendidos e reunidos sob o conceito de rule of law, ou Estado de Direito. Apoia-se sobre o fato de que o referido princípio teria uma função quase-constitucional, servindo como marco regulatório para atuação administrativa, judicial e legislativa do Estado hospedeiro em face dos investidores, posicionando-o acima de todo objeto e propósito dos tratados de investimento. Afirma que o tratamento justo e equitativo não deve ser compreendido como uma garantia absoluta, mas como um princípio que permite o equilíbrio entre a proteção do investimento e o interesse público do Estado hospedeiro. ${ }^{100}$

Afirma, também, que o tratamento justo e equitativo desenvolve-se por meio de exigências cada vez mais específicas, que os sistemas jurídicos nacionais têm de incorporar a fim de cumprir com os tratados internacionais de investimento. Ensina, assim, que este padrão assumiria uma função "comparável à do direito constitucional interno", porém com duas modificações: só constitui um regime especial para os investidores estrangeiros e só enseja danos caso o Estado hospedeiro viole suas obrigações contratuais.

Aponta que dessa forma a jurisprudência dos tribunais arbitrais de investimento revela-se não na forma de decisões fragmentadas em um agregado desordenado dentro deste cenário, mas como expressão da emergência contínua de um regime global para governança do investimento estrangeiro e da conduta dos Estados hospedeiros a este relacionados.

\footnotetext{
100 SCHILL, Stephan W. Fair and Equitable Treatment under Investment Treaties as an Embodiment of the Rule of Law. Global Administrative Law Series. IILJ Working Paper 2006/6. Disponível em: <http://www.iilj.org/ publications/2006-6Schill.asp>. Acesso em: 22 maio 2013. p. 10.
}

Importante que se anote que a forma proposta de aplicação do princípio do tratamento justo e equitativo repercute necessariamente na esfera interna dos Estados hospedeiros, notadamente em sua estrutura institucional e em seu arcabouço processual. Nos Estados, a base para a implementação dessas mudanças seria, primeiramente, por óbvio, a consolidação do modelo democrático capaz de assegurar a vigência do Estado de Direito e, portanto, a garantia da segurança jurídica, tanto no âmbito do próprio Estado quanto no âmbito das relações internacionais e transnacionais, que mantiverem ou que o fizerem seus nacionais. ${ }^{101}$

É necessário que os Estados forneçam um sistema jurídico justo e eficiente de resolução de litígios judiciais para a revisão dos atos administrativos e para resolução de litígios entre as partes. $\mathrm{O}$ autor compara as obrigações decorrentes do tratamento justo e equitativo aplicadas aos procedimentos judiciais com as obrigações decorrentes dos instrumentos de direitos humanos, tais como o Art. $6^{\circ}$ da Convenção Europeia dos Direitos Humanos. Cita, como exemplo, o caso Azinian v. México, ocasião em que o Tribunal destacou que "uma denegação de justiça poderia ser invocada, se os tribunais se recusassem a instaurar um processo, sujeitasse o caso à demora injustificada, ou se administrasse a justiça de forma inadequada". ${ }^{102}$ Desse modo, o tratamento justo e equitativo concede um direito de acesso a um tribunal para os investidores estrangeiros. ${ }^{103}$

Schill sugere uma metodologia a ser seguida por estes tribunais encarregados da solução de controvérsias em investimentos na concretização deste padrão e na resolução de conflitos entre os interesses divergentes de Estados hospedeiros e investidores. Nesse bojo, indica que os tribunais deveriam empregar um método comparativo entre o direito doméstico e internacional, abrangendo a compreensão da repercussão da aplicação do direito na esfera doméstica e levando em conta a jurisprudência de outros tribunais internacionais também. ${ }^{104}$

Ou seja, pretende o autor destacar a importância da observância da cultura jurídica interna para compreensão da dinâmica institucional e das regras e posicionamentos adota-

101 SCHILL, Stephan W. Fair and Equitable Treatment under Investment Treaties as an Embodiment of the Rule of Law. Global Administrative Law Series. IILJ Working Paper 2006/6. Disponível em: <http://www.iilj.org/ publications/2006-6Schill.asp>. Acesso em: 22 maio 2013. p. 33/34.

102 Robert Azinian, Kenneth Davitian, E Ellen Baca v. The United Mexican States, ICSID Case No. ARB (AF)/97/2, Final Award of Nov. 1, 1999, par. 102

103 SCHILL, Stephan W. Fair and Equitable Treatment under Investment Treaties as an Embodiment of the Rule of Law. Global Administrative Law Series. IILJ Working Paper 2006/6. Disponível em: <http://www.iilj.org/ publications/2006-6Schill.asp>. Acesso em: 22 maio 2013. p. 26.

104 SCHILL, Stephan W. Fair and Equitable Treatment under Investment Treaties as an Embodiment of the Rule of Law. Global Administrative Law Series. IILJ Working Paper 2006/6. Disponível em: <http://www.iilj.org/ publications/2006-6Schill.asp>. Acesso em: 22 maio 2013. p. 29. 
dos de acordo com cada caso, respeitadas as circunstâncias. O mesmo se aplicaria ao direito internacional, devendo ser levadas em consideração, por exemplo, a jurisprudência de cortes internacionais, como a da Corte Europeia de Direitos Humanos ou a do Órgão de Apelação da OMC, e princípios como os do Direito Administrativo Europeu. ${ }^{105}$ Destaca que, mediante esta observância, reforça-se a justificativa da interpretação que é dada caso a caso, dando maior credibilidade à tomada de decisão por estes órgãos.

Ressalta-se que a compreensão de como essas esferas aplicam o direito é essencial para que sejam proferidas decisões justas, sem resquícios de arbitrariedade ou de parcialidade em prol de uma ou de outra parte, sempre, porém, levando em consideração o fim priorizado no contexto dos tratados de investimentos internacionais: o da proteção e promoção do investimento estrangeiro entre as partes contratantes. ${ }^{106}$ Atingido este fim, estar-se-á também trabalhando para atingir o fim último da promoção e proteção do investimento estrangeiro direto, consistente no estímulo ao crescimento econômico e ao desenvolvimento. ${ }^{107}$

Em última instância, além de ser defendida a função regulatória do Direito Administrativo Global no campo do investimento como forma de promover o equilíbrio entre as partes nas controvérsias destas relações, a correta aplicação dos princípios do tratamento justo e equitativo tem o importante papel de estimular a democratização e o aperfeiçoamento dos modelos jurídico-institucionais dos Estados hospedeiros, fazendo com que se adequem aos padrões internacionais. No contexto atual, o desempenho dessa tarefa representa significativo auxílio, sobretudo, aos países em desenvolvimento.

\section{Conclusão}

Como acertadamente ensina Alvarez, ${ }^{108}$ a tendência que vem se confirmando é a do desaparecimento de uma hegemonia dos países do norte sobre os do sul, no que toca à direção dos fluxos de investimento, tal como ocorreu inicialmente. No quadro atual, a prática do investimento en-

\footnotetext{
105 SCHILL, Stephan W. Fair and Equitable Treatment under Investment Treaties as an Embodiment of the Rule of Law. Global Administrative Law Series. IILJ Working Paper 2006/6. Disponível em: <http://www.iilj.org/ publications/2006-6Schill.asp>. Acesso em: 22 maio 2013. p. 30.

106 SCHILL, Stephan W. Fair and Equitable Treatment under Investment Treaties as an Embodiment of the Rule of Law. Global Administrative Law Series. IILJ Working Paper 2006/6. Disponível em: <http://www.iilj.org/ publications/2006-6Schill.asp>. Acesso em: 22 maio 2013. p. 30.

107 SCHILL, Stephan W. Fair and Equitable Treatment under Investment Treaties as an Embodiment of the Rule of Law. Global Administrative Law Series. IILJ Working Paper 2006/6. Disponível em: <http://www.iilj.org/ publications/2006-6Schill.asp >. Acesso em: 22 maio 2013. p. 31.

108 ALVAREZ, José E. The Public International Law Regime Governing International Investment. Recueil des cours, v. 344. Pocketbooks of the Hague Academy of International Law, 2009. p. 347
}

contra seus atores das nacionalidades mais diversas, como já apontado neste estudo, sendo gradualmente enfraquecido o caráter exclusivamente extrativista das relações de investimento anteriores, fundadas sobre acordos entre países ricos que buscavam o lucro mediante o uso dos recursos de países em desenvolvimento.

Embora se confirmem as tendências de celebração de instrumentos mais justos entre as partes para o regramento do investimento estrangeiro entre empresas e governos locais, a fim de que seja evitada a proteção excessiva dos atores não estatais, essencial é a presença de um regramento mais estável, capaz de controlar e de limitar as relações de investimento, pois as pressões exercidas pelas multinacionais ocidentais e também por aquelas originárias das novas economias emergentes serão sempre decisivas no momento de elaboração da estrutura desses acordos e da condução do processo.

$\mathrm{O}$ posicionamento do Estado no centro da atividade regulatória no modelo sui generis do Direito Administrativo Global revela o caráter conflitante do diálogo entre soft law e hard law. ${ }^{109}$ Verificou-se que regimes com aspirações universais, como o da OMC e o das Nações Unidas, não seriam mais a escolha da maioria dos Estados. Da mesma forma, as instituições tomadas pela política e pelo sistema da proteção diplomática não vigoraram no passado e padecem de sérios problemas de legitimidade e credibilidade no presente.

Por outro lado, a prática constatada hoje no cenário do investimento apresenta-se como alternativa às propostas até então apresentadas (e sabidamente frustradas) de regulação para estas relações. O mecanismo de resolução de conflitos, neste campo, remete-nos à perspectiva da ocorrência de mudanças, pautadas pelo aumento da qualidade de fundamentação, pelo estabelecimento de padrões com embasamento concreto para boa administração do Estado e pelo reconhecimento dos órgãos responsáveis pela resolução de disputas investidor-Estado, de que são ambos procedimento e sujeitos do Direito Administrativo Global e, portanto, também peças chaves na condução desta evolução. ${ }^{110}$

A repercussão das decisões proferidas nas disputas de investimento emergentes de tratados bilaterais, assim como a

109 HELLWIG, Guilherme Centenario. A crise financeira e as soluções internacionais. CONGRESSO INTERNACIONAL: As integrações regionais e os indivíduos. 20123 e 4 de dezembro de 2012, Porto Alegre. Porto Alegre: Faculdade de Direito da Universidade Federal do Rio Grande do Sul, 2012.

110 KINGSBURY, Benedict; SCHILL, Stephan. Investor-State Arbitration as Governance: Fair and Equitable Treatment, Proportionality and the Emerging Global Administrative Law. Public Law and Legal Theory Research Paper Series. Working Paper n. 09-46. New York: New York University School of Law, 2009. Disponível em: <http://ssrn.com/abstract=1466980>. Acesso em: 11 jan. 2013. p. 52. 
práxis da resolução desses casos, pode vir a se consolidada, no cenário global, como um corpo capaz de pautar a atividade dos atores envolvidos no cenário internacional, caso seguidos os princípios e parâmetros propostos pelo Direito Administrativo Global, notadamente daqueles decorrentes da interpretação do conteúdo do padrão de tratamento justo e equitativo. A eventual formação de padrões de decisões nesse cenário poderá, além de auxiliar na formação de decisões de casos futuros semelhantes, desempenhar importante papel no nivelamento da qualidade e padronização da atitude das jurisdições nacionais perante as relações de investimento.

Por essa razão, de grande dimensão é a potencial influência que esse mecanismo poderá exercer sobre a condução dos assuntos atinentes ao investimento estrangeiro direto no futuro. Diante da tendência que se afirma cada vez mais forte, de exercício desta atividade regulatória pela atividade arbitral no campo do investimento, e parte desta estrutura de governança que se forma, deve-se ter a garantia de que esta atuação esteja pautada por um conjunto de regras e princípios legitimadores desta prática, a fim de que o deslinde não seja arbitrário e tendencioso por influência da parte mais abastada da disputa.

Nessa esteira, os teóricos do regime que propõem a reorganização do cenário internacional pelos princípios, regras e procedimentos do Direito Administrativo Global, desde o início, deixam claro que suas aspirações não são as de democratizar as relações internacionais que têm lugar sob a égide de regimes e sistemas de direito internacional. O que se procura é reduzir as clivagens que hoje dificultam o ingresso daqueles atores menos favorecidos, que se colocam em posição de inferioridade, devido ao seu menor potencial econômico e de influência política na esfera internacional.

Dentro desse contexto, para que o Direito Administrativo Global possa de fato inspirar confiança e ter a repercussão idealizada, é essencial que seja dada legitimidade a estes regimes, por meio da introdução de mecanismos de fiscalização e de responsabilização institucional, promovendo-se a participação efetiva na construção e condução deste sistema, tanto pelos atores pressionados quanto pelas figuras e forças dominantes na clássica dinâmica norte-sul. Acredita-se que a promoção da participação nas estruturas e regimes já existentes seria a resposta capaz de trazer resultados de modo mais célere e efetivo aos clamores urgentes de reorganização do cenário internacional, do que a criação de um novo sistema, fundado sobre nova dinâmica, para esta disciplina.

O regime de investimento revela-se um valioso campo de estudos para temas recorrentes em outros regimes internacionais, tais como a resistência a pressões provenientes de diversos polos e a falta de técnicas para responsabilização dos árbitros perante uma instituição superior. As justificati- vas normativas para o aperfeiçoamento do sistema arbitral para resolução de disputas de investimento hoje existentes ultrapassam os argumentos já conhecidos (e contestáveis) de que promoveria a otimização do investimento estrangeiro direto para a alocação eficiente de recursos.

Muito mais do que isso, por meio de um regime dotado de mecanismos adequados de responsabilização, da via recursal aos laudos exauridos em primeira análise, de transparência em fazer os documentos acessíveis ao público, fundamentando adequadamente as decisões tomadas, ficando abertos à submissão a mecanismos de revisão, para citar alguns exemplos de questões a serem aprimoradas, seria dada maior atenção às questões que constituem as maiores demandas nesta seara: o clamor por transparência e responsabilização, voltadas à defesa da correta administração do Estado e à proteção de direitos e outros interesses pertinentes.

O Direito Administrativo Global emergente pode desempenhar importante papel na condução das reformas necessárias, provendo valioso auxílio prático e normativo a este respeito. A inspiração na estrutura administrativa verificada na esfera nacional constitui grande vantagem para o aperfeiçoamento do modelo proposto. Aliando-se este estudo ao aprofundamento da teoria democrática global e transnacional, se estará traçando uma via para solução de questões relativas à diversidade, à igualdade e à justiça na esfera global, para o estabelecimento de um regime global para o investimento justo e legítimo, capaz de oferecer igualdade de tratamento para todos envolvidos nestas relações.

\section{RefERÊNCIAS}

ALVAREZ, José E. The Public International Law Regime Governing International Investment. Recueil des cours, v. 344. Pocketbooks of the Hague Academy of International Law, 2009.

ALVAREZ, José E.; KHAMSI, Kathryn. The Argentine Crisis and Foreign Investors: A Glimpse into the Heart of the Investment Regime. Global Administrative Law Series. IILJ Working Paper 2006/6. Disponível em: <http://mmw.iilj.org/ publications/2008-5Alvarez-Khamsi.asp>. Acesso em: 22 maio 2013

BITENCOURT NETO, Eurico. Direito Administrativo Transnacional. Revista Eletrônica de Direito Administrativo Econômico - REDAE. n. 18, Maio/Jun./Jul. 2009. Salvador. Disponível em: <http://www.direitodoestado.com/revista/ REDAE-18-MAIO-2009-EURICO-BITENCOURT.pdf $>$. Acesso em: 22 maio 2013

CNUCED. Global Investment Trends Monitor. n. 11, 2013. 
Disponível em: < http://unctad.org/en/PublicationsLibrary/webdiaeia2013d1_en.pdf>. Acesso em: 11 jan. 2013

CUNHA, Bruno Santos. Resenha: O direito administrativo sem Estado: crise ou fim de um paradigma? Revista Digital de Direito Público, v. 1. 1, n. 1, p. 242-244, 2012. Disponível em: <wnw.direitorp.usp.br/periodicos>. Acesso em: 22 maio 2013

FRANCK, Susan. Development and Outcomes of Investment Treaty Arbitration. Harvard International Law Journal, v. 50, n. 2, 2009; Washington \& Lee Legal Public Legal Studies Research Paper Series. Working Paper n. 2009. Disponível em: <bttp://papers.ssrn.com/sol3/papers.cfm?abstract_id=1406714>. Acesso em: 11 jan. 2013

FERREIRA, Luciano Vaz; MOROSINI, Fábio Costa. As Consequências da Corrupção no Fluxo Transnacional de Investimento Estrangeiro Direto: Estudo Preliminar. In: SEMINÁRIO BRASILEIRO DE ESTUDOS ESTRATÉGICOS INTERNACIONAIS SEBREEI: Integração Regional e Cooperação Sul-Sul no Século XXI. 2012, Porto Alegre. Anais... Porto Alegre, 2012.

GRAHME F, Thompson. The constitutionalization of the global corporate sphere? Oxford: Oxford University Press, 2012.

GUZMAN, Andrew T. "Why LDCs Sign Treaties That Hurt Them: Explaining the Popularity of Bilateral Investment Treaties", 38 Virginia Journal of International Law, 639, 1998.

HELLWIG, Guilherme Centenario. A crise financeira e as soluções internacionais. CONGRESSO INTERNACIONAL: As integrações regionais e os indivíduos. 20123 e 4 de dezembro de 2012, Porto Alegre. Porto Alegre: Faculdade de Direito da Universidade Federal do Rio Grande do Sul, 2012.

ICSID Website. Disponível em: < https://icsid.worldbank.org/ ICSID $/$ FrontServlet? requestType $=$ CasesRH\&actionVal $=$ RightFr

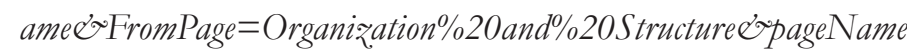
=Organization $>$. Acesso em: 11 jan. 2013

KINGSBURY, Benedict; KIRSCH, Nico; STEWART, Richard B. The Emergence of Global Administrative Law. Global Administrative Law Series. IILJ Working Paper 2004/1. Disponível em: <http://www.ïlj.org/GAL/documents/TheEmergenceofGlobalAdministrativeLaw.pdf>. Acesso em: 11 jan. 2013

KINGSBURY, Benedict; SCHILL, Stephan. Investor-State Arbitration as Governance: Fair and Equitable Treatment, Proportionality and the Emerging Global Administrative Law. Public Law and Legal Theory Research Paper Series. Working Paper n. 09-46. New York: New York University School of Law, 2009. Disponível em: <http://ssrn.com/abstract $=1466980>$. Acesso em: 11 jan. 2013

KINGSBURY, Benedict; STEWART, Richrd B. Perspectives on the Development of Global Administrative Law in Latin
America. El nuevo derecho administrativo global en América Latina. Buenos Aires: Rap, 2009. Disponível em: <http:// iilj.org/GAL/documents/GALBAbook.Introduction.pdf>. Acesso em: 22 maio 2013

MACDONALD, Euan. GAL and the nature of Bilateral Investment Treaty (BIT) tribunals. Global Administrative Law - A blog dedicated to the continued development of the global administrative law (GAL) project: highlighting new events and publications and providing a forum for discussion and debate. Disponível em: <http://globaladminlaw.blogspot.com.br/2008/03/galand-nature-of-bilateral-investment.html $>$. Acesso em: 22 maio 2013

MAGNOTTTA, Fernanda Petená. Multipolaridade e multilateralismo: o G20 e a relação entre poder e governança no século XXI. In: ENCONTRO NACIONAL ABRI 2011, 3., 2011, São Paulo. Associação Brasileira de Relações Internacionais, Instituto de Relações Internacionais - USP. Disponível em: <http://www.proceedings.scielo.br/scielo. php?script $=$ sci_arttext\&pid=MSC000000012201100020001 $0 \& \operatorname{lng}=$ en\&nrm $=a b n>$. Acesso em: 22 maio 2013

MONT'T, Santiago. What international investment law and Latin America can and should demand from each other. Updating the Bello/Calvo doctrine in the BIT generation. Revista Argentina del Regimen de la Administración Publica. Rap: Buenos Aires, 2007. Disponível em: <http://www.iilj.org/ GAL/documents/montt.pdf>. Acesso em: 22 maio 2013

POULSEN, Lauge Skovgaard; HUFBAUER, Gary Clyde. Foreign Direct Investment in Times of Crisis. Working Paper Series 11-3. Washington: Peterson Institute for International Economics, 2011. p. 3-4.

RIPINSKI, Sergey. Stephan W. Schill. The Multilateralization of International Investment Law - Book Review. European Journal of International Law, v. 22, n. 2, p. 598-602. Oxford: Oxford University Press, 2011. Disponível em: <http:// ejil.oxfordjournals.org/content/22/2/598.full.pdf + html $>$. Acesso em: 11 jan. 2013.

SANCHEZ, Michelle Ratton. The Global Administrative Law Project: a review from Brazil. In: HAUSER GLOBALIZATION COLLOQUIUM FALL 2008: Global Governance and Legal Theory. NYU Law School: New York, 2008. Disponível em: <http://www.iilj.org/courses/documents/ Sanchez-GALProjectReviewfromBrazil.pdf $>$. Acesso em: 22 maio 2013

SCHILL, Stephan W. Fair and Equitable Treatment under Investment Treaties as an Embodiment of the Rule of Law. Global Administrative Law Series. IILJ Working Paper 2006/6. Disponível em: <http://www.iilj.org/publications/20066Schill.asp>. Acesso em: 22 maio 2013 
SCHILL, Stephan W. The Multilateralization of International Investment Law. Online Proceedings, Working Paper n. 18/08. London: Society of International Economic Law, 2008. Disponível em: <http://www.ssrn.com/link/SIEL-InauguralConference.html $>$. Acesso em: 11 jan. 2013

SLAUGHTER, Anne-Marie. A New World Order. Princeton: Princeton Univerity Press, 2004.

SLAUGHTER, Anne-Marie. Global Government Networks, Global Information Agencies, and Disaggreagated Democracy. Working Paper n. 18. Cambridge: Harvard Law School, 2001. Disponível em: <http://papers.ssrn.com/sol3/papers. cfm?abstract_id=283976>. Acesso em: 11 jan. 2013

UNCTAD. Course on Dispute Settlement, 2006. Disponível em: < http://r0.unctad.org/disputesettlement/course.htm>. Acesso em: 11 jan. 2013

VAN HARTEN, Gus; LOUGHLIN, Martin. Investment Treaty Arbitration as a Species of Global Administrative Law. European Journal of International Law. v. 17, n. 1. p. 121 150. Oxford: Oxford University Press, 2006. Disponível em: <http://ejil.oxfordjournals.org/>. Acesso em: 11 jan. 2013

VAN HARTEN, Gus. A Case for an Internaional Investment Court. Society for International Economic Law. Working Paper n. 22/2008. Disponível em: <http://www.ssrn.com/link/ SIEL-Inaugural-Conference.html>. Acesso em: 11 jan. 2013 VAN HARTEN, Gus. Arbitrator Behaviour in Asymmetrical Adjudication: An Empirical Study of Investment Treaty Arbitration. Research Paper Series. Research Paper n. 41/2012.
Toronto: Oosgode Hall Law School, 2012. Disponível em: $<$ http:/ ssrn.com/abstract $=2149207>$. Acesso em: 11 jan. 2013

VAN HARTEN, Gus. Fairness and Independence in Investment Arbitration: A Critique of Susan Franck's 'Development and Outcomes of Investment Treaty Arbitration'. ITN Quarterly, Dezembro, 2010. Disponível em: <http://www.iisd.org/ itn/>. Acesso em: 11 jan. 2013

VAN HARTEN, Gus. Investment Treaty Arbitration, Procedural Fairness, and the Rule of Law. Draft forthcoming in SCHILL (ed.). International Investment Law and Comparative Public Law. Oxford: Oxford University Press, 2010. Disponível em: <http://papers.ssrn.com/sol3/papers.cfm?abstract_ $\mathrm{id}=1658523>$. Acesso em: 11 jan. 2013

VAN HARTEN, Gus. Private Authority and Transnational Governance: The Contours of the International System of Investor Protection. 12 Review of Int I Political Economy. 600, 2005. Disponível em: <http://papers.ssrn.com/sol3/ papers.cfm?abstract_id=1468690>. Acesso em: 11 jan. 2013

WORLD BANK. Multipolarity: The New Global Economy. 104117, 2011. Disponível em: <http://siteresources.worldbank. org/INTGDH/Resources/GDH_CompleteReport2011. pdf $>$. Acesso em : 11 jan. 2013

Case:

Robert Azinian, Kenneth Davitian, \& Ellen Baca v. The United Mexican States, ICSID Case No. ARB (AF)/97/2, Final Award of Nov. 1, 1999. 
Para publicar na Revista de Direito Internacional, acesse o endereço eletrônico www.rdi.uniceub.br ou www.brazilianjournal.org.

Observe as normas de publicação, para facilitar e agilizar o trabalho de edição. 